\title{
El derecho de acceso a los medicamentos como corolario de la acción internacional contra medicamentos ilegales
}

\author{
Right of access to medicines as corollary of international \\ action against illegal medical products
}

\author{
Daniel GarCÍA SAN JosÉ \\ Catedrático de Derecho Internacional Público y Relaciones Internacionales \\ Universidad de Sevilla \\ dagarcia@us.es
}

Resumen: Se defiende abordar el problema de acceso a medicamentos seguros, combinando los discursos económico y humanista, que buscan proteger los derechos de propiedad intelectual frente a la falsificación de medicamentos, y al mismo tiempo hacer efectivo el derecho de acceso a medicinas esenciales a precios asequibles en todo el mundo. Se avanzan claves para regular el acceso a medicamentos seguros como un global common de carácter intangible, prefiriendo la acción concertada de los sujetos y actores implicados en la salud humana a la propuesta de un nuevo Convenio sobre salud global que descartamos a partir de la reciente experiencia del Convenio MEDICRIME.

Palabras clave: salud global; acceso a medicamentos seguros; falsificación de medicinas y salud pública; cuestiones de interés general y respuesta normativa de la comunidad internacional de estados en su conjunto; convenio MEDICRIME.
Abstract: This study defends the need to address the problem of access to safe medicines, combining economic and humanistic discourses that seek to protect intellectual property rights against counterfeiting of medicines, while at the same time making the right to access essential medicines at affordable prices around the world. We advance various clues for the international community regulating access to safe medicines as a global common of intangible nature, opting in for the concerted action of the subjects and actors involved in human health, as the best option instead of the proposal of a new Convention on Global Health like the MEDICRIME Convention.

Keywords: Global Health; Access to secure medicines; Counterfeiting of medicines and public health; Global concern and legal responses of the international community of States as a whole; MEDICRIME Convention.

Sumario: I. INTRODUCCIÓN: EL ACCESO A MEDICAMENTOS SEGUROS ES UN PROBLEMA GLOBAL QUE REQUIERE UNA APROXIMACIÓN MULTILATERAL. II. LAS DOS CARAS DEL ACCESO A MEDICAMENTOS SEGUROS A ESCALA MUNDIAL. 1. La dimensión económica y la lucha coordinada de la comunidad internacional contra la falsificación de medicamentos. 2. La dimensión humana y el derecho a la salud global en la Agenda 2030. III. ¿UN CONVENIO INTERNACIONAL SOBRE SALUD GLOBAL QUE ASEGURE EL DERECHO DE ACCESO A MEDICAMENTOS SEGUROS? 1. El Convenio MEDICRIME del Consejo de Europa como referente a seguir. 2. Análisis crítico del Convenio MEDICRIME. IV. CLAVES DE UNA ACCIÓN INSTITUCIONALIZADA DE LA COMUNIDAD INTERNACIONAL PARA EL ACCESO A MEDICAMENTOS SEGUROS COMO UN GLOBAL COMMON DE CARÁCTER INTANGIBLE A PARTIR DEL GLOBAL HEALTH LAW. V. CONCLUSIÓN. VI. BIBLIOGRAFÍA.

* Estudio realizado en el marco de la Red de excelencia: «Bioderecho Internacional y Europeo: desafíos actuales» Referencia: DER2015-71828-REDT, del MINECO. 


\section{INTRODUCCIÓN: EL ACCESO A MEDICAMENTOS SEGUROS COMO UN PROBLEMA GLOBAL QUE REQUIERE UNA APROXIMACIÓN MULTILATERAL}

E

n nuestro tiempo la globalización de la salud es una realidad que no admite discusión, ya sea desde el punto de vista de los riesgos y amenazas a la salud a escala global ${ }^{1}$, como desde el prima de la cooperación y regulación internacional de la salud ${ }^{2}$. Como afirma el profesor Pons, «la noción holística, transversal e internacional por su propia naturaleza de salud global, conduce a su caracterización como un bien público global que debe ser internacionalmente protegido» ${ }^{3}$. De este modo, siguiendo al profesor Faraminán, podría considerarse la salud global como un global common de carácter intangible de la especie humana ${ }^{4}$.

A partir de la consideración de la salud global como una cuestión de interés general, sería igualmente defendible considerar como parte del mismo el acceso seguro a las medicinas esenciales sin discriminación, en su doble acepción: negativa, en el sentido de no permitir la comercialización de medicamentos ilegales (falseados, falsificados o defectuosos) que son una amenaza para la salud pública; y positiva, en cuanto a la garantía de accesibilidad física y de asequibilidad de dichas medicinas esenciales ${ }^{5}$. La interconexión entre ambas dimensiones parece evidente. De hecho, en el $5^{\circ}$ encuentro del Mecanismo de Estados Miembros de la Organización Mundial de la Salud ${ }^{6}$, celebrado a finales de 2016, se ha puesto de manifiesto la creciente relación entre la falta de acceso

1 Gostin, L. O., Global Health Law, Harvard, Harvard University Press, 2014, pp. 32-58. Considerando, como hace este autor, los desplazamientos masivos de la población mundial y la realización de un comercio global de mercancías.

2 Pons Rafols, X., «International Law and Global Health: an overview», Paix et Securité Internationales, $\mathrm{n}^{\circ} 3,2015$, p. 36.

3 Ibid., p. 59.

4 FARAMIÑÁn GILBERT, J. M., «De los espacios de interés internacional a los global commons», en J. Alcaide Fernández, E. Petit de Gabriel (eds.), España y la Unión Europea en el Orden Internacional, Tirant lo Blanch, Valencia, 2017, pp. 833 y ss.

5 VAN ROMPAEY, K., «Salud global y derechos humanos: propiedad intelectual, derecho a la salud y acceso a los medicamentos», Anuario de Derecho Constitucional Latinoamericano, vol. XV, 2009, p. 499. Como señala esta autora, los problemas de accesibilidad y asequibilidad se concretan, por un lado, en el precio de medicamentos producidos por las empresas farmacéuticas, considerando criterios de rentabilidad económica y que están protegidos por patentes. Esos mismos criterios económicos inciden, por otro lado, en las inversiones en $\mathrm{I}+\mathrm{D}$ que evitan hacer esas empresas en relación con determinadas enfermedades que sufren mayoritariamente poblaciones que viven en extrema pobreza y no podrían comprarlas, caso de producirlas (como el mal de chagas, la encefalitis letárgica o la enfermedad del sueño).

6 Creado por la Resolución WHA 65.19, de 26 de mayo de 2012 relativa a Substandard/Spurious/ Falsely-labelled/Falsified/Counterfeit (SSFFC) Medical Products. 
o escasa disponibilidad de medicinas y la aparición de productos médicos ilegales $(\ll \text { SSFFC } \gg \text { en sus siglas en inglés })^{7}$. Sin embargo, como constata Karen Van Rompaey: «paradójicamente, en la era de la globalización y la biotecnología las enfermedades infecciosas continúan matando a diez millones de personas por año, $90 \%$ de las cuales viven en el mundo en desarrollo. Sólo el 15\% de la población mundial consume el $90 \%$ de la producción farmacéutica» ${ }^{8}$.

En mi opinión, considerar la salud global como un global common de carácter intangible de la especie humana, implica la exigencia de defender una visión integradora en relación con el acceso a medicamentos que afecten a la salud pública: la TRIPS-based approach que toma en consideración los legítimos intereses económicos de las empresas farmacéuticas, junto con la HUMAN RIGHTS-based approach, que reivindica el derecho a la salud como imperativo categórico frente al que deben ceder cualesquiera otras consideraciones. Realmente, ambas aproximaciones son complementarias e interdependientes, como las dos caras de una misma moneda ${ }^{9}$ y esa convergencia se refleja fielmente en la perspectiva integradora defendida (global commons-based approach) para alcanzar una regulación internacional -inexistente a día de hoy- que combine la lucha coordinada de la comunidad internacional contra la falsificación de medicamentos junto con los medios necesarios para asegurar el derecho de acceso a medicamentos seguros en cualquier parte del mundo. En las siguientes páginas desarrollaré con más detalle esta idea.

\section{LAS DOS CARAS DEL PROBLEMA DEL ACCESO A MEDICAMENTOS}

\section{SEGUROS A ESCALA MUNDIAL}

\section{La dimensión económica y la lucha coordinada de la comunidad internacional contra la falsificación de medicamentos}

La Declaración Ministerial de Doha sobre Salud Pública y Comercio, de 20 de noviembre de $2001^{10}$, permite a los Estados un margen de flexibilidad

7 Las siglas responden a la conceptualización seguida en el seno de la Organización Mundial de la Salud: Substandard/Spurious/Falsely-labelled/Falsified/Counterfeit Medical Products. Resolución WHA 65.19, de 26 de mayo de 2012.

8 VAN RompaEY, K., «Salud global y derechos humanos:...», op. cit., p. 499.

9 Siguiendo el pensamiento de autores como la profesora OrTEga GómEZ, M., «El derecho de acceso a los medicamentos y el derecho de patentes en países en desarrollo», Revista de Bioética y Derecho, $\mathrm{n}^{\circ} 37,2016$, pp. 26-36.

10 En https://www.wto.org/spanish/thewto_s/minist_s/min01_s/mindecl_trips_s.htm [visitado: 22 de mayo de 2017]. 
en el cumplimiento de las obligaciones asumidas en el marco del Acuerdo de la Organización Mundial del Comercio sobre los Aspectos de los Derechos de Propiedad Intelectual relacionados con el Comercio (ADPIC) ${ }^{11}$. Sin embargo, los efectos negativos de la protección de patentes en detrimento de la accesibilidad a medicamentos esenciales son claramente muy significativos en los países en desarrollo debido a la acción de las empresas farmacéuticas que presionan a gobiernos más o menos débiles para adoptar legislaciones que no desarrollan las potencialidades de excepciones al ADPIC ${ }^{12}$. No resulta sorprendente que el 20 de abril de 2012, el Tribunal Superior de Kenia dictaminara nula la definición de «falsificación» incluida en la Anti Counterfeit Act $2008^{13}$-que llegó incluso a establecer una Agencia antifraude, única en África Subsahariana-. Esa legislación respondía a la campaña mundial contra la falsificación de medicamentos dirigida en Kenia y otros países de África Subsahariana por las empresas titulares de derechos de propiedad intelectual, con un resultado que -en opinión de los autores-implicaba una restricción de acceso a medicinas esenciales ${ }^{14}$.

Los autores vienen defendiendo desde hace años la necesidad de articular las obligaciones de las empresas farmacéuticas bajo el derecho a la salud junto con mecanismos de rendición de cuentas para afrontar la actual grave crisis global de falta de acceso a medicinas esenciales ${ }^{15}$. De ahí que desde la doctrina se haya defendido la necesidad de contar con un tratado internacional de

11 El Acuerdo sobre los ADPIC es el Anexo 1C del Acuerdo de Marrakech por el que se establece la Organización Mundial del Comercio, firmado en Marraquech el 15 de abril de 1994. Puede consultarse en www.wipo.int/treaties/es/textjsp?file_id=305906 [visitado: 22 de mayo de 2017].

12 Grover, A. et al., «Pharmaceutical Companies and Global Lack of Access to Medicines: Strengthening Accountability under the Right to Health», Fournal of Law, Medicine and Ethics, vol. 40, $\mathrm{n}^{\circ} 2,2012$, p. 236.

13 Que sustituía a una normativa anterior de 2001, a fin de cumplir con los compromisos asumidos en el ADPIC. Vid. Harrington, J. y O'Hare, A., «Framing the National Interest: Debating Intellectual Property and Access to Essential Medicines in Kenya», The fournal of World Intellectual Property, vol. 17, $\mathrm{n}^{\circ} 1-2,2014$, pp. 16-33.

14 Von BRawn, J. y MunuY, P., «New Enforcement Mechanisms Challenge the Legality of Genesis in the Name of Public Health: The Emergence of Anti-Counterfeit Legislation in East Africa», African fournal of International and Comparative Law, vol. 18, $\mathrm{n}^{\circ} 2$ 2, 2010, pp. 238-253. Como señalan estos autores que comentan el fallo del Tribunal Supremo de Kenia, asumiendo como valor prevalente el derecho a la vida y a la salud, la controvertida definición era demasiado ambigua y podía provocar incautaciones arbitrarias de medicamentos genéricos bajo el pretexto de luchar contra la falsificación de productos médicos.

15 Grover, A. et al., «Pharmaceutical Companies and Global Lack of Access to Medicines: Strengthening Accountability under the Right to Health», op. cit., p. 237. 
tipo marco sobre el derecho a la salud global (Framework Convention on Global Health) que establezca procedimientos que mejoren la coordinación, la cooperación y la colaboración global sobre cuestiones de salud global, empezando por la urgente necesidad de acceso a medicinas ${ }^{16}$. Según estos autores, este Convenio marco podría encontrar su fundamento en el artículo 12 del Pacto Internacional de Derechos Económicos, Sociales y Culturales a la luz de su interpretación en el Comentario General n ${ }^{\circ} 14$, en el Convenio n ${ }^{\circ} 187$ de la Organización Internacional del Trabajo relativo al marco promocional para la seguridad y salud en el trabajo, en vigor desde el 20 de febrero de $2009^{17}$, en la Convención relativa a la eliminación de todas las formas de discriminación contra la mujer de 16 de diciembre de $1983^{18}$, y en la Convención sobre los derechos del niño de 20 de noviembre de $1989^{19}$. En este mismo sentido, el Convenio del Consejo de Europa ${ }^{\circ} 211$ relativo a la falsificación de productos médicos y delitos similares que supongan una amenaza para la salud pública (Convenio MEDICRIME) ${ }^{20}$ contiene un novedoso e importante artículo 11, relativo a la responsabilidad de las personas jurídicas ${ }^{21}$ que podría servir de inspiración para un eventual Convenio marco.

16 Ibid., p. 245.

17 En http://www.ilo.org/dyn/normlex/es/f?p=NORMLEXPUB:12100:0::NO::P12100_ILO_ CODE:C187 [visitado: 22 de mayo de 2017].

18 BOE núm. 69, de 21 de marzo de 1984.

19 BOE núm. 313, de 31 de diciembre de 1990.

20 Convenio MEDICRIME, CETS No. 211. BOE núm. 286, de 30 de noviembre de 2015.

21 Artículo 11 del Convenio MEDICRIME. Responsabilidad de las personas jurídicas. 1. Cada Parte adoptará las medidas legislativas y de otra índole que sean necesarias, para que las personas jurídicas puedan ser declaradas responsables de los delitos tipificados en el presente Convenio, cuando sean cometidos por cuenta de aquellas por una persona física, que actúe de forma individual o en condición de miembro de un órgano de la persona jurídica en cuyo seno ejerza un poder de dirección que dimane de:

a. un poder de representación de la persona jurídica;

b. una autorización para tomar decisiones en nombre de la persona jurídica;

c. una autorización para ejercer control en el seno de la persona jurídica.

2. Fuera de los casos previstos en el párrafo 1, cada Parte adoptará las medidas legislativas y de otra índole que sean necesarias para garantizar que una persona jurídica pueda ser declarada responsable cuando la ausencia de vigilancia o de control por parte de cualquier persona física mencionada en el párrafo 1 haya permitido la comisión de un delito tipificado con arreglo al presente Convenio por cuenta de la mencionada persona jurídica por una persona física que actúe bajo su autoridad.

3. La responsabilidad de la persona jurídica podrá resolverse en sede penal, civil o administrativa, dependiendo de los principios jurídicos propios de la Parte.

4. Esta responsabilidad se establecerá sin perjuicio de la responsabilidad penal de las personas físicas que hayan cometido la infracción. 
Un Convenio marco definitivamente clarificaría las obligaciones de los actores no estatales -incluyendo las empresas farmacéuticas- bajo el derecho a la salud. Sin embargo, en mi opinión, no es la única posibilidad. En el Comentario General n ${ }^{\circ} 14$ del Comité de Derechos Económicos Sociales y Culturales, relativo a la interpretación del artículo 12 del Pacto Internacional de Derechos Económicos, Sociales y Culturales, puede leerse -en relación con el derecho a la salud- una interesante referencia a la responsabilidad de los actores no estatales:

«Si bien sólo los Estados son partes en el Pacto y, por lo tanto, responsables de su cumplimiento, todos los miembros de la Sociedad, individuos, incluidos los profesionales de la salud, las familias, las comunidades locales, las organizaciones intergubernamentales y no gubernamentales, las organizaciones de la sociedad civil y las empresas privadas tienen responsabilidades en relación con la realización del derecho a la salud. Por consiguiente, los Estados Partes deben proporcionar un entorno que facilite el desempeño de estas responsabilidades» ${ }^{22}$.

De igual modo, la Declaración de los Objetivos del Milenio ${ }^{23}$ reconocía la responsabilidad de las empresas farmacéuticas en relación con el derecho a la salud, por ejemplo, en su objetivo 8. e): «En cooperación con las compañías farmacéuticas, proporcionar acceso a medicamentos esenciales y asequibles en los países en desarrollo» ${ }^{24}$.

En desarrollo de la responsabilidad internacional de las empresas farmacéuticas -bajo el derecho a la salud-de facilitar el acceso a medicinas esenciales a precios asequibles, viene trabajando en los últimos años el Relator Especial sobre el derecho a la salud, Paul Hunt, a través de sus Human Rights Guidelines for Pharmaceutical Companies in Relation to Access to Medicines ${ }^{25}$ que, como su propio nombre indica, no pasan de ser meras recomendaciones o sugerencias dirigidas a las empresas farmacéuticas sobre cómo deberían actuar para hacer

22 UN Doc. E/C.12/2000/4, parágrafo 42.

23 Resolución A/RES/55/2, adoptada por la Asamblea General de Naciones Unidas el 13 de septiembre de 2000. Disponible en www.un.org/spanish/milenio/ares552.pdf [visitado: 22 de mayo de 2017].

24 LeE, J.-Y. y Hunt P., «Human Rights Responsibilities of Pharmaceutical Companies in Relation to Access to Medicines», Fournal of Law, Medicine and Ethics, vol. 40, issue 1, 2012, p. 221.

25 UN Doc. A/63/263, de 11 de agosto de 2008, Anexo. Disponible en http://www.who.int/medicines/areas/human_rights/A63_263.pdf [visitado: 22 de mayo de 2017]. 
frente a sus responsabilidades bajo el derecho a la salud, a las que se refería el Comité de Derechos Económicos, Sociales y Culturales en su Comentario General $n^{\circ} 14$. En términos concretos, esta responsabilidad de las empresas farmacéuticas respecto del derecho a la salud podría sustentarse, como ha defendido la profesora Ortega Gómez, apelando al principio de la responsabilidad social de las empresas farmacéuticas, por ejemplo, mediante la donación de patentes, pasando por la licencia obligatoria, las sublicencias concedidas o mediante la moratoria de la entrada en vigor del ADPIC para los países menos desarrollados, o mediante un sistema de precios diferenciados siempre que los Estados se comprometan a reforzar los controles aduaneros que eviten eventuales desvíos comerciales de medicamentos a precio reducido destinados, en principio, sólo a los países en desarrollo ${ }^{26}$. A su vez, los Estados deben garantizar el derecho de acceso a los medicamentos que precisen las personas dependientes de su jurisdicción, preservando la innovación farmacéutica. Ello implica, indefectiblemente luchar contra los medicamentos ilegales en su acepción más amplia (medicamentos falsificados, falseados y deficientes). Es evidente, en cualquier caso que la solución pasa por una acción concertada de todas las partes concernidas, ya sean sujetos (Estados y Organizaciones intergubernamentales) o actores internacionales (sociedad civil y empresas) ${ }^{27}$.

Tras el Acuerdo de la Organización Mundial del Comercio sobre los Aspectos de los Derechos de Propiedad Intelectual relacionados con el Comercio (ADPIC), el precio de las medicinas no sólo se ha encarecido de manera considerable sino que, además, se ha suscitado la cuestión de si las medicinas esenciales deben o no ser objeto de patentes, generando una profusa literatura al respecto.

Además, la legítima defensa de los derechos de propiedad intelectual a veces choca con el derecho de acceso a medicinas genéricas cuando transitan por el territorio de Estados en los que esas patentes despliegan sus efectos. Así, por ejemplo, en 2008 y 2009 funcionarios de aduana de la Unión Europea interceptaron 19 envíos de medicamentos genéricos, la mayoría en Holanda, en tránsito a través de la Unión Europea -procedían principalmente de la India y tenían por destino países como Brasil, Colombia, Ecuador, México,

26 Ortega Gómez, M., «El derecho de acceso a los medicamentos y el derecho de patentes en países en desarrollo», op. cit., p. 36.

27 QUICK, J. D., «Ensuring access to essential medicines in the developing countries: A framework for action», Clinical Pharmacology \& Therapeutics, vol. 73, issue 4, 2003, pp. 279-282. 
Nigeria, Perú, Portugal y España- aplicando el Reglamento 1383/200328, que permitía la adopción de medidas contra mercancías que infringen los derechos de propiedad intelectual, incluidas las mercancías en tránsito. Se trataba de sospechas de infracción de patentes, aunque los productos no estaban patentados ni en el país de exportación ni en el país de destino. Brasil, India y otros países expresaron su preocupación por estas detenciones en las reuniones del Consejo de los ADPIC de la Organización Mundial del Comercio en marzo y junio de 2009. En julio de 2011, India y la Unión Europea llegaron a un entendimiento: mientras no hubiera pruebas suficientes de una probabilidad real de desvío de medicamentos en tránsito a través de la UE no existían motivos para que las autoridades aduaneras de un Estado miembro de la UE sospechara de una infracción de la patente. Aunque se trate de medicamentos sujetos a patente en el territorio de la Unión Europea ${ }^{29}$.

Por todo ello, la dimensión económica ha de ser concertada con la dimensión humana. Así parece haberse entendido por los redactores del Convenio MEDICRIME, una de cuyas características destacadas es que, frente a la aproximación de la protección de los derechos de propiedad intelectual, se asume como uno de sus tres ejes vectores (las tres «p» de penalizar, proteger y promover, en el artículo 1 relativo al objeto y finalidad de este Convenio) ${ }^{30}$, la protección de la salud pública y, con ello, la perspectiva de las víctimas. En este punto hay que advertir, sin embargo, que la consideración de las víctimas en el Convenio MEDICRIME no permite analizarlo desde la aproximación de los tratados de protección de derechos humanos, considerando que la salud pública es utilizada como la salud de la comunidad, no como la salud física y mental de cada uno de los ciudadanos que integran una determinada comunidad, a

28 Reglamento (CE) No 1383/2003 del consejo de 22 de julio de 2003 relativo a la intervención de las autoridades aduaneras en los casos de mercancías sospechosas de vulnerar determinados derechos de propiedad intelectual y a las medidas que deben tomarse respecto de las mercancías que vulneren esos derechos. DOUE L 196/7 de 2 de agosto de 2003.

29 Liberman, J., «Combating Counterfeit Medicines and Illicit Trade in Tobacco Products: Minefields in Global Health Governance», Fournal of Law, Medicine and Ethics, vol. 40, issue 2, 2012, p. 332 .

30 De conformidad con su preámbulo, persecución penal, protección de las víctimas y promoción de la cooperación internacional: «Teniendo en cuenta la necesidad de elaborar un instrumento internacional centrado en los aspectos relacionados con la prevención, la protección de las víctimas y el derecho penal en materia de lucha contra todas las formas de falsificación de productos médicos y delitos similares que supongan una amenaza para la salud pública... Debe fomentarse una estrecha cooperación internacional entre los Estados miembros y los Estados no miembros del Consejo de Europa». 
pesar de los graves riesgos por acción u omisión que plantean para derechos tan universalmente aceptados como el derecho a la vida, a la integridad física y psíquica y a la salud de cualquier persona ${ }^{31}$. Esto es, como un global common o cuestión de interés general de primer orden, como la protección de la capa de ozono o la prevención del deshielo ártico. Por ello, la perspectiva de las víctimas no debería exagerarse a la hora de valorar el alcance de este instrumento internacional. Ciertamente, lo previsto en los artículos $19^{32}$ y $20^{33} \mathrm{del}$

31 Los compuestos básicos de una medicina legal pueden ser omitidos en su copia falsificada o, incluso peor, pueden contener sustancias altamente tóxicas como metales pesados o pesticidas en su composición fraudulenta. MAGES, R., «Counterfeit medicines: threat to patient health and safety», Pharmaceuticals Policy and Law, vol. 18, $\mathrm{n}^{\circ}$ 1-4, 2016, pp. 163-177. No se olvide que los falsificadores de medicamentos están más preocupados por copiar la apariencia externa de un medicamento que sus efectos beneficiosos para la salud. PowELL, A., «Benchmark Legislation: A Measured Approach in the Fight against Counterfeit Pharmaceuticals», Hastings Law fournal, vol. 61, 2010, p. 751.

32 Artículo 19 del Convenio MEDICRIME. Protección de las víctimas. Cada Parte adoptará las medidas legislativas y de otra índole que sean necesarias para proteger los derechos y el interés de las víctimas, y en particular: a. velarán por que las víctimas tengan acceso a la información pertinente relativa a su caso y que sea necesaria para la protección de su salud; b. asistirán a las víctimas en su recuperación física, psicológica y social; c. velarán porque su Derecho interno contemple el derecho de las víctimas a ser indemnizadas por los autores de los delitos.

33 Artículo 20 del Convenio MEDICRIME. Situación de las víctimas durante la investigación y el procedimiento penal. 1. Cada Parte adoptará las medidas legislativas y de otra índole que sean necesarias para proteger los derechos y el interés de las víctimas en todas las fases de la investigación y del procedimiento penal, y en particular: a. les informarán de sus derechos y de los servicios de los que disponen y, a menos que no deseen recibir esa información, del seguimiento de su denuncia, de los cargos imputados, del estado general de la investigación o de la tramitación del procedimiento, de su papel en el mismo y de la resolución que se dicte en el asunto que les incumbe; b. les permitirán, de conformidad con las normas procesales del Derecho interno, ser oídas, presentar elementos de prueba y elegir la forma de exponer sus opiniones, necesidades y preocupaciones, ya sea directamente o a través de un intermediario, así como la forma en que se han de tener en cuenta; c. pondrá a su disposición los servicios de apoyo adecuados para que sus derechos e intereses sean debidamente presentados y tenidos en cuenta; d. tomará las medidas efectivas necesarias para garantizar su protección y la de sus familiares y testigos de cargo frente a intimidaciones y represalias. 2. Cada Parte garantizará a las víctimas, desde su primer contacto con las autoridades competentes, acceso a la información sobre los procedimientos judiciales y administrativos pertinentes. 3. Cada Parte velará por que las víctimas que tengan la condición de parte en un procedimiento penal tengan acceso, cuando se den las circunstancias, al beneficio de justicia gratuita. 4. Cada Parte adoptará las medidas legislativas y de otra índole que sean necesarias para que las víctimas de un delito tipificado con arreglo al presente Convenio y cometido en el territorio de una Parte distinta de aquella en la que residan, puedan formular su denuncia ante las autoridades competentes de su Estado de residencia. 5. Cada Parte regulará, a través de medidas legislativas o de otra índole y de conformidad con las condiciones establecidas en su legislación interna, la posibilidad de que grupos, fundaciones, asociaciones y organizaciones gubernamentales o no gubernamentales presten asistencia y/o ayuda a las víctimas, con el consentimiento de éstas, en el curso de los procedimientos penales en los que se enjuicien delitos tipificados con arreglo al presente Convenio. 
Convenio MEDICRIME es relevante pero quizás insuficiente pues se delega en los Estados partes el dotar de contenido lo previsto en dichas disposiciones, lo que se hará previsiblemente en concordancia con el nivel de desarrollo de los instrumentos de garantía y supervisión existentes en materia de control de medicamentos falsificados. Esto es, aquellos Estados que cuenten con sistemas más perfeccionados, con seguridad articularán mejores garantías de protección para las víctimas que aquellos otros Estados que carezcan de los mismos ${ }^{34}$. De ahí que pueda afirmarse que más allá de la genérica referencia a la cooperación internacional de los Estados parte para la protección de las víctimas, prevista en el artículo $22^{35}$, hubiera sido deseable establecer una unidad de atención a las víctimas, con carácter internacional y dependiente del propio Consejo de Europa, de un modo similar al existente en la Corte Penal Internacional ${ }^{36}$.

Más aún, como han destacado algunos autores, es muy difícil, por no decir casi imposible salvo en muy contados casos, probar la condición de víctima de un medicamento falsificado, al menos en primera instancia ante tribunales nacionales ${ }^{37}$. De hecho, se podría haber insistido más aún en la prevención de estas conductas, trabajando en la concienciación de los pacientes -los que adquieren los medicamentos falsificados- vinculando en este sentido a las empresas farmacéuticas. La aproximación frente a la falsificación de medicamentos debe ser integral, atendiendo a las fuentes (los criminales) pero también a sus destinatarios (los pacientes consumidores de esas medicinas fraudulentas). En este sentido, coincido con autores como Eric Tardiff cuando apunta a que la eficacia del Convenio MEDICRIME va a depender de que paralelamente se fortalezcan las instituciones de los países donde prospera el negocio de los

34 Algunos autores, sin embargo, son de una opinión distinta, valorando muy positivamente y como suficiente, el tratamiento conferido a las víctimas de productos médicos falsificados en el Convenio MEDICRIME. Vid. inter alia, KeITEL, S., «The MEDICRIME Convention: criminalizing the falsification of medicines and similar crime», Generics and Biosimilars Initiative fournal, vol. 1, issue 3-4, 2012, pp. 138-141.

35 Artículo 22 del Convenio MEDICRIME. Cooperación internacional en materia de prevención y de otras medidas administrativas. 1. Las Partes cooperarán entre sí a fin de prestar protección y asistencia a las víctimas.

36 La Unidas de Apoyo a las Víctimas y Testigos, con carácter subsidiario a la Secretaría de la Corte Penal Internacional, prevista en los arts. 16 a 19 de las Reglas de Procedimiento y Prueba aprobadas en el Primer Período de Sesiones de la Asamblea de Estados Partes en el Estatuto de Roma celebrado en Nueva York del 3 al 10 de septiembre de 2002 (ICC-ASP/1/3 y corr. 1), Parte II. A.

37 Venhuis, B. J. et al., «Operation resistance: A snapshot of falsified antibiotics and biopharmaceutical injectables in Europe», op. cit., p. 398. 
medicamentos falsificados, junto con el fomento de una cultura de rechazo en la sociedad frente a los medicamentos falsificados ${ }^{38}$.

En todo caso, de lo expuesto en este epígrafe puede desprenderse la idea que la aproximación económica. Por sí sola, es insuficiente en una efectiva estrategia de la comunidad internacional para asegurar el acceso a medicamentos seguros a escala mundial. Es necesario su complementación con una dimensión humana.

\section{La dimensión humana: el Derecho a la salud global en la AGENDA 2030}

Asumir una aproximación integral y global con respecto al acceso seguro a las medicinas supone tres condiciones: asumir un lenguaje común a todas las partes concernidas, en primer lugar; aceptar la conexión entre falsificación de productos médicos y derecho de acceso a medicamentos esenciales, en segundo lugar; y finalmente, establecer cauces de cooperación institucionalizada en los que participen los Estados, Organizaciones Internacionales y los actores no estatales.

La Resolución aprobada por la Asamblea General de Naciones Unidas, el 25 de septiembre de 2015 «Transformar nuestro Mundo: la Agenda 2030 para el Desarrollo Sostenible ${ }^{39}$, contiene un objetivo 3 «Garantizar una vida sana y promover el bienestar de todos a todas las edades», que en su subapartado 8 es concretado en: «logar la cobertura sanitaria universal, incluida la protección contra los riesgos financieros, el acceso a servicios de salud esenciales de calidad y el acceso a medicamentos y vacunas inocuos, eficaces, asequibles y de calidad para todos» (cursiva es añadida). En opinión de la doctrina mayoritaria, los medicamentos falsificados no son inocuos, eficaces y de calidad, sino todo lo contrario. De ahí el gran acierto del Convenio MEDICRIME de destacar que suponen una grave amenaza para la salud pública y la necesaria protección de las víctimas de tales productos. Más allá de este hecho, sin embargo, la conexión entre falsificación de medicamentos y derecho de acceso a medicamentos esenciales parece ir más allá, cuando en la Resolución que contiene los Objetivos del Desarrollo Sostenible se ha incluido el término «asequible» trascen-

\footnotetext{
38 TARDIFF, E., «Medicamentos falsificados: una píldora difícil de tragar y un reto sanitario global», Anuario Español de Derecho Internacional, vol. 27, 2011, p. 608.

39 Doc. A/Res/70/1.
} 
diendo la dimensión meramente económica y dando paso a la humana. En este sentido, la definición de medicamentos falsificados no debe ser construida sólo desde la protección de los derechos de propiedad intelectual de las empresas farmacéuticas sino, además y por encima de ellos, desde la perspectiva del derecho a la salud ${ }^{40}$.

Ya hemos visto en el epígrafe anterior que la Declaración de los Objetivos del Milenio reconocía la responsabilidad de las empresas farmacéuticas en relación con el derecho a la salud, por ejemplo, en su objetivo 8. e): «En cooperación con las compañías farmacéuticas, proporcionar acceso a medicamentos esenciales y asequibles en los países en desarrollo». Como ha escrito el profesor Sanahuja, las metas globales previstas primero en los Objetivos del Milenio y luego en los Objetivos de Desarrollo Sostenible (Agenda 2030) han de verse como «normas multilaterales no vinculantes dentro del ámbito del soft law, que tratan de conciliar las necesidades de coordinación y acción colectiva con el principio de soberanía nacional. Ello debilita su efectividad, pero al mismo tiempo, al reflejar metas en gran medida aspiracionales más que obligaciones jurídicas, es posible su aceptación por parte de los Estados. Ello permite definir consensos internacionales que proporcionen un mandato a los organismos multilaterales, y a su vez situar las políticas nacionales en ese marco, en un proceso voluntario de 'multilateralización' de las mismas» ${ }^{41}$.

Un examen crítico de la Agenda 2030, sin embargo, arroja cuatro lastres o impedimentos para creer que baste la acción de las Naciones Unidas para hacer efectivo el derecho a la salud de todos en su doble dimensión de lucha contra la falsificación de medicamentos y en la adopción de medidas que hagan posible el acceso a medicamentos y vacunas inocuos, eficaces, asequibles y

40 Esta idea se refuerza en el sub apartado 3.b, dentro del Objetivo 3 de la Agenda 2030 para el Desarrollo Sostenible cuando se afirma la necesidad de «apoyar las actividades de investigación y desarrollo de vacunas y medicamentos contra las enfermedades transmisibles y no transmisibles que afectan primordialmente a los países en desarrollo y facilitar el acceso a medicamentos y vacunas esenciales asequibles de conformidad con la Declaración relativa al Acuerdo sobre los Aspectos de los Derechos de Propiedad Intelectual Relacionados con el Comercio y la Salud Pública, en la que se afirma el derecho de los países en desarrollo a utilizar al máximo las disposiciones del Acuerdo sobre los Aspectos de los Derechos de Propiedad Intelectual Relacionados con el Comercio y la Salud Pública y, en particular, proporcionar acceso a los medicamentos para todos». (La cursiva es añadida).

41 Sanahuja, J. A., «Entre Westfalia, Southwestfalia y Cosmópolis: la Gobernanza Global del Desarrollo Sostenible en el Horizonte 2030», en C. García Segura (dir.), La tensión cosmopolita, Tecnos, Madrid, 2016, p. 271. 
de calidad para todos: el principio de obligaciones compartidas pero diferenciadas; las contradicciones y lagunas internas en las obligaciones asumidas por los Estados; la presencia distorsionadora de múltiples actores con diferentes roles a jugar; y un mecanismo de control del cumplimiento/seguimiento de la Agenda muy débil.

Primer lastre: el principio de obligaciones compartidas pero diferenciadas (principio $7^{\circ}$ de la Declaración de Río) que es ahora la piedra angular de la Agenda $2030^{42}$. Es uno de los precios del consenso: acuerdo de mínimos con grandes concesiones que suscitan el riesgo de fragmentar la Agenda, en la práctica, en tantas mini agendas como Estados estén llamados a cumplirla, a la luz de sus circunstancias nacionales. Este hecho va a ser un claro obstáculo para el cumplimiento de los objetivos del desarrollo sostenible, en general, y el acceso a medicamentos y vacunas inocuos, eficaces, asequibles y de calidad para todos» ${ }^{43}$.

Segundo lastre: las contradicciones y lagunas internas en las obligaciones asumidas por los Estados. La visión idílica del futuro que se presenta en los parágrafos 7 a 9 del Documento «Transformar nuestro mundo: La Agenda 2030 para el Desarrollo Sostenible», se contradice con la perspectiva estatocén-

42 Ver el parágrafo 5 del documento «Transformar nuestro mundo: La Agenda 2030 para el Desarrollo Sostenible» anexo a la Resolución A/69/ L. 85, adoptada por la Asamblea General el 12 de agosto de 2015: «La presente Agenda... Todos los países la aceptan y se aplica a todos ellos, aunque teniendo en cuenta las diferentes realidades, capacidades y niveles de desarrollo de cada uno y respetando sus políticas y prioridades nacionales»). Asimismo, en el parágrafo 21: «Todos trabajaremos para implementar la Agenda... Teniendo en cuenta las diferentes realidades, capacidades y niveles de desarrollo de cada país y respetando sus políticas y prioridades nacionales. Respetaremos también el margen normativo nacional para su crecimiento económico sostenido, inclusivo y sostenible». En el parágrafo 55: «Los objetivos de desarrollo sostenible y sus metas son de carácter integrado e indivisible, de alcance mundial y de aplicación universal, tienen en cuenta las distintas realidades, capacidades y niveles de desarrollo de cada país y respetan sus políticas y prioridades nacionales. Si bien las metas expresan las aspiraciones a nivel mundial, cada gobierno fijará sus propias metas nacionales, guiándose por la ambiciosa aspiración general pero tomando en consideración las circunstancias del país. Cada gobierno decidirá también la forma de incorporar esas aspiraciones y metas mundiales en los procesos de planificación, las políticas y las estrategias nacionales».

43 A modo de ejemplo, considerando la meta 8.7 del documento «Transformar nuestro mundo: La Agenda 2030 para el Desarrollo Sostenible» ¿cómo lograrla si se debe respetar el margen de apreciación nacional a nivel normativo de cada Estado? Véase la meta 17.15, en este mismo sentido («Respetar el liderazgo y el margen normativo de cada país para establecer y aplicar políticas orientadas a la erradicación de la pobreza y la promoción al desarrollo sostenible»). 
trica que es la piedra angular de la Declaración (la soberanía nacional y la defensa del interés nacional, como pervivencia de un modelo clásico de sociedad internacional) ${ }^{44}$. Algunas metas son muy confusas $^{45}$ y otras metas no van acompañadas de fecha para su cumplimiento $[3.8,3$. a) a 3. d), relativa a salud, vacunas, gestión de riesgos para la salud humana; 4. a) relativa a la construcción de escuelas, y ello pese al tenor rimbombante del parágrafo 25 (educación) y del parágrafo 26 (salud) del citado Documento ${ }^{46}$.

Tercer lastre: la presencia distorsionadora de múltiples actores con diferentes roles a jugar, que no están claramente definidos en la Agenda 203047. Hay tres tipos de actores implicados en las alianzas propuestas: los países, las partes interesadas y todas las personas ${ }^{48}$, si bien el catalizador de la acción colectiva en pro del desarrollo sostenible siguen siendo los Estados. La primera clarificación de quiénes son las partes interesadas la encontramos en el parágrafo 39 (al referirse a que la implementación de esta amplia y ambiciosa nueva agen-

44 A título de ejemplo, el parágrafo 20 del documento «Transformar nuestro mundo: La Agenda 2030 para el Desarrollo Sostenible», cuya inclusión es loable, se contradice con el parágrafo siguiente (21) que recuerda a las reservas introducidas en tratados de protección de derechos humanos por países que practican la sharia, discriminando entre hombres y mujeres en cuanto al alcance de la protección conferida a ellos en virtud de tales tratados. A mayor abundamiento, ¿qué significa la referencia a la migración en el parágrafo 29? Es tan ambigua su redacción que no permite deducir si está reconociendo o prohibiéndola. Tampoco queda claro qué es un turismo sostenible en el parágrafo 33. La referencia a los derechos humanos en el parágrafo 35 desaparece en el objetivo 16 al que hace alusión dicho parágrafo.

45 Véanse la meta 11.4 «Redoblar los esfuerzos para proteger y salvaguardar el patrimonio cultural y natural del mundo»; la 12.6 «alentar a las empresas... (p. 26); la 17.2: «Velar...», etc. Frente a otras que son más concretas como, por ejemplo, la meta 13. A) respecto de la lucha contra el cambio climático.

46 Notorio es el caso del objetivo 5 «Lograr la igualdad entre los géneros y empoderar a todas las mujeres y niñas», con ninguna de sus metas estando acompañada de fecha de consecución. El objetivo 10 (reducir la desigualdad en y entre países) tampoco lleva fecha en la mayoría de sus metas (10.3 a 10.7). El objetivo 16 (Promover sociedades pacíficas e inclusivas para el desarrollo sostenible, facilitar el acceso a la justicia para todos y crear instituciones eficaces, responsables e inclusivas a todos los niveles, además de no hacer referencia expresa a los derechos humanos (a pesar del parágrafo 35) no incluye fecha para la mayoría de sus metas 16.1 a 16.3, 16.5 a 16.8, 16.10 a) y b).

47 Ya desde el Preámbulo ( $2^{\circ}$ párrafo) del documento «Transformar nuestro mundo: La Agenda 2030 para el Desarrollo Sostenible» se alude a los países y a las partes interesadas a fin de establecer una alianza de colaboración. Al margen de algunas evocaciones más propias del imaginario colectivo: «la humanidad», «el planeta» ( $4^{\circ}$ párrafo del Preámbulo), «el pueblo» (parágrafo 52).

48 Confer penúltimo párrafo del Preámbulo del documento «Transformar nuestro mundo: La Agenda 2030 para el Desarrollo Sostenible», op. cit. 
da requiere una alianza mundial para el desarrollo sostenible... «Aglutinando a los gobiernos, el sector privado, la sociedad civil, el sistema de Naciones Unidas y otras instancias, movilizando los recursos disponibles». La pregunta pertinente es que siendo todas «partes interesadas», ¿coinciden los intereses de cada de las partes?

En el parágrafo 41 del Documento «Transformar nuestro mundo: La Agenda 2030 para el Desarrollo Sostenible» se avanza aún más en la precisión de quiénes son las partes interesadas: «Reconocemos el papel que desempeñan los diversos integrantes del sector privado, desde las microempresas y las cooperativas, hasta las multinacionales, y la función de las organizaciones de la sociedad civil y las organizaciones filantrópicas en la implementación de la nueva Agenda». En términos aún más precisos: ¿es similar el interés en el desarrollo sostenible de una fundación como la de Bill y Melisa Gates, que dedicó cerca de 3.000 millones de dólares al desarrollo en 2012, al de Médicos Sin Fronteras? ¿Es comparable el interés de las empresas farmacéuticas titulares de derechos de patentes respecto de fármacos de elevado precio al de otras empresas farmacéuticas que comercializan medicamentos genéricos? ${ }^{39}$

El parágrafo 60 del Documento que venimos comentando se apoya en la Alianza Mundial revitalizada para respaldar el cumplimiento de todos los objetivos y metas, aglutinando a los gobiernos, la sociedad civil, el sector privado, el sistema de Naciones Unidas y otras instancias, y movilizando todos los recursos disponibles». No es una novedad, si se recuerda la iniciativa del Pacto Mundial. Lo novedoso es que ahora parece llevarse esta alianza hasta sus últimas consecuencias. En este sentido, el sector privado tiene específicamente atribuido un papel en el Mecanismo de Facilitación de la Tecnología, que se estableció en la Agenda de Acción de Addis Abeba ${ }^{50}$.

En el mecanismo de seguimiento y examen del progreso de cumplimiento de los objetivos del desarrollo sostenible por los Estados, de carácter voluntario, podrán participar presentando informes todas las partes interesadas ${ }^{51}$,

49 Al hilo de esta cuestión, por ejemplo, la meta 12.6: «Alentar a las empresas, en especial, a las grandes empresas y las empresas transnacionales, a que adopten prácticas sostenibles e incorporen informaciones sobre la sostenibilidad en su ciclo de presentación de informes». ¿A qué les está comprometiendo realmente? ¿Qué implica la meta 17.3: «Movilización de recursos financieros adicionales procedentes de múltiples fuentes para los países en desarrollo»?

50 Parágrafo 70 del documento «Transformar nuestro mundo: La Agenda 2030 para el Desarrollo Sostenible», op. cit.

51 Ibid., parágrafo 74.d). 
pero dejando claro su papel secundario con respecto a los Estados ${ }^{52}$.Se prevé igualmente que, a nivel mundial, el Foro Político de Alto Nivel -que se reunirá cada cuatro años bajo los auspicios de la Asamblea General a fin de proporcionar orientación política de alto nivel sobre la Agenda y su implementación- desempeñará un papel central en la supervisión de una red de procesos mundiales de seguimiento y examen ${ }^{53}$, previéndose que en los exámenes respectivos se contará con la participación de todos los interesados pertinentes, quienes, en la medida de lo posible, harán aportaciones» ${ }^{54}$.

Cuarto lastre: un mecanismo de control del cumplimiento/seguimiento de la Agenda muy débil debido, básicamente, a dos razones: políticas -la falta de voluntad de los Estados de exigir un cumplimiento más allá de los desiderativoy objetivas, en concreto, la incertidumbre respecto de qué datos y por quiénes se habrán de elaborar.

De los cuatro lastres apuntados éste puede parecer sin duda el más grave para asegurar el acceso a medicamentos y vacunas inocuos, eficaces, asequibles y de calidad para todos, por varias razones. En primer lugar, las obligaciones -a pesar de la referencia a 2030- son de comportamiento, ya evidenciado desde el segundo párrafo del Preámbulo («Nos comprometemos a trabajar sin descanso a fin de conseguir la plena implementación de esta Agenda para 2030»). En segundo lugar, están las cláusulas de escape que hacen aún más difícil cualquier intento de rendición de cuentas. Señala en este sentido el parágrafo 12 del documento que venimos comentando que se tendrá como punto de partida el principio de obligaciones compartidas, $\mathrm{y}$ «que tengan en cuenta las diferentes realidades, capacidades y niveles de desarrollo de cada uno y respetando sus políticas y prioridades nacionales», junto con el pleno respeto a su margen normativo nacional y reafirmando la plena soberanía permanente de cada Estado sobre la totalidad de su riqueza, sus recursos naturales y su actividad económica, y que la ejercerá libremente ${ }^{55}$.

52 Ibid., parágrafo 76 in fine.

53 Ibid., parágrafos 82 y ss.

54 Ibid., parágrafo 85. A tenor de este texto no cabe sin o preguntarse ¿cómo van a participar? ¿Siguiendo un modelo parecido a la Organización Internacional del Trabajo, es decir, con delegaciones nacionales integradas por tres tipos de representantes (gobierno, patronal, fuerzas sindicales)? O ¿tendrán vida propia y autónoma conforme aumente su peso económico y científico en la Agenda para el desarrollo sostenible? En todo caso, ¿están justificados los temores que apuntan a que condicionarán la Agenda y la labor de Naciones Unidas?

55 Ibid., parágrafo 18. 
Cada país es el principal responsable de su propio desarrollo económico y social ${ }^{56}$. En consecuencia, cada gobierno será el principal responsable del seguimiento y examen, en el plano nacional, regional y mundial, de los progresos conseguidos en el cumplimiento de los objetivos y las metas durante los próximos quince años ${ }^{57}$. A tenor del parágrafo 48 parece haberse pensado en un sistema parecido al de los informes periódicos que los Estados presentaban a la Comisión de Derechos Humanos de Naciones Unidas sobre su grado de cumplimiento de los derechos y libertades enunciados en la Declaración Universal de los Derechos Humanos. Ese mecanismo, muy desacreditado por su utilización política y su inoperancia dejó de existir junto con la propia Comisión, sustituida en 2006 por el Consejo de Derechos Humanos, pues si bien respondía a la lógica de la movilización de la vergüenza, en palabras del profesor Pastor Ridruejo, se había convertido en la inmovilización de los sinvergüenzas ${ }^{58}$.

Junto a razones de índole política, el problema añadido a un control ya de por sí débil estriba en la pretensión de aplicar datos que midan los progresos y aseguren que nadie se quede atrás. Ahora bien, no se dice por quién o quiénes se van a elaborar y, caso de optarse por expertos independientes (no políticos), queda por dirimir si sus conclusiones estarán o no supeditadas a posterior aceptación por los Estados. En la lucha contra el cambio climático, el contar con datos creíbles y aceptables por todos ha sido vital y no se ha logrado sino hasta muy recientemente ${ }^{59}$. En lo que respecta al acceso a medicinas esenciales, la elaboración de la «Model list» de la Organización Mundial de la Salud viene siendo objeto de críticas desde hace años por los criterios de su elaboración $^{60}$.

De la importancia de los medios de implementación da cuenta el hecho de que se ha querido consagrar como metas concretas en la Agenda (la 17.18 y la 17.19) afirmándose al respecto que «las metas relativas a los medios de implementación son fundamentales para poner en práctica nuestra Agenda y

56 Ibid., parágrafo 41.

57 Ibid., parágrafo 47.

58 Pastor Ridruejo, J. A., Curso de Derecho Internacional Público y Organizaciones Internacionales, $9^{\text {a }}$ ed., Tecnos, Madrid, 2007, p. 204.

59 Vid. García San José, D., «Seguridad medioambiental y principio de necesidad en Bioderecho internacional», en Bioderecho, Seguridad y Medioambiente, en José Manuel Sánchez Patrón et al. (coords.), Tirant lo Blanch, Valencia, 2015, pp. 132-150.

60 Barbui, C. y Purgato, M., «Decisions on WHO's essential medicines need more scrutiny»; British Medical fournal, vol. 349, 2014, p. 1. 
tienen la misma importancia que los demás objetivos y metas» ${ }^{61}$. Se trata de un proceso de seguimiento y examen de la implementación de la presente Agenda, de carácter voluntario ${ }^{62}$, basado en la confianza y comprensión mutua entre todas las naciones ${ }^{63}$. Los procesos de seguimiento y examen se regirán por los principios consagrados en el parágrafo 74 , destacando su carácter voluntario para los países ${ }^{64}$, aprovechando los procesos y plataformas existentes, cuando los haya, reduciendo al mínimo la carga que supone la presentación de informes para las administraciones nacionales ${ }^{65}$, debiendo ser vigorosos y con base empírica ${ }^{66}$. Se prevé además una cooperación «adecuada» entre los sectores público y privado para aprovechar una amplia gama de datos pero serán los propios países quienes se encarguen de apoyar y observar los progresos ${ }^{67}$. Se entiende así, que en el parágrafo 75, al referirse a los indicadores mundiales que elaborará el Grupo Interinstitucional y de Expertos sobre los indicadores de los Objetivos de Desarrollo Sostenible, será acordado por la Comisión de Estadística de las Naciones unidas a no más tardar en marzo de 2016, para ser aprobado por el Consejo Económico y Social y la Asamblea General, afirmando a continuación que «mantendrá su equilibrio político». Con respecto al control a nivel mundial, por parte del Foro Político de Alto Nivel, valen las observaciones realizadas al respecto en el tercer lastre (en relación con las aportaciones que podrían hacer las partes interesadas, conforme al parágrafo 85).

\section{III. ¿UN CONVENIO INTERNACIONAL SOBRE SALUD GLOBAL QUE ASEGURE EL DERECHO DE ACCESO A MEDICAMENTOS SEGUROS?}

\section{El Convenio MEDICRIME del Consejo de Europa como referente a seguir}

El 1 de enero de 2016 entró en vigor el Convenio MEDICRIME relativo a la falsificación de productos médicos y delitos similares que supongan una amenaza para la salud pública. Este tratado internacional tiene varias lectu-

61 Parágrafo 61 del documento «Transformar nuestro mundo: La Agenda 2030 para el Desarrollo Sostenible», op. cit.

62 Ibid., parágrafo 72.

63 Ibid., parágrafo 73.

64 Ibid., parágrafo 74.a).

65 Ibid., parágrafo 4.f).

66 Ibid., parágrafo 74.g).

$67 \mathrm{Ibid}$., parágrafo 76. 
ras posibles: desde el ordenamiento jurídico interno de los Estados que son parte en el mismo ${ }^{68}$ pero también, y sobre todo, desde el plano del Derecho Internacional. Considerando su naturaleza, el Convenio MEDICRIME es un «non self-executing treaty on criminal-law»; esto es, un tratado internacional de carácter no auto ejecutorio que, por su contenido material, requiere de los Estados que sean partes en el mismo, la adopción de medidas en su Derecho interno tendentes a considerar como delitos penales la falsificación de medicamentos y de productos similares, sin perjuicio de incluir otras disposiciones de carácter procesal, por ejemplo, en relación con las víctimas de estas conductas criminales. No establece derechos ni obligaciones dirigidas a personas físicas o jurídicas, sino que impone -con carácter flexible- obligaciones de resultado ${ }^{69}$ y de comportamiento a los Estados -en especial, la cooperación internacional-70 $y$, en este sentido, es un ejemplo clásico de instrumento convencional regido con carácter supletorio a lo convenido expresamente por los Estados parte en el mismo por lo dispuesto en la Convención de Viena de 23 de mayo de 1969 sobre Derecho de tratados ${ }^{71}$.

Adoptado en el seno de una Organización Internacional regional, el Consejo de Europa, está abierto a todos los Estados de la comunidad internacional, por lo tanto, puede considerarse como un tratado multilateral sobre una cuestión de interés general para todos los Estados. Cuenta con un mecanismo de control del cumplimiento de obligaciones asumidas por los Estados parte muy blando ${ }^{72}$ : un órgano intergubernamental, el Comité de las Partes que está previsto en el artículo 23 y siguientes -por su composición, en principio más

68 A título de ejemplo, véase la Ley Orgánica 1/2015, de 30 de marzo, por la que se modifica la Ley Orgánica 10/1995, de 23 de noviembre, del Código Penal tipificando nuevas conductas e incrementando las penas de acuerdo a lo establecido en este Convenio. BOE núm. 77, de 31 de marzo de 2015.

69 Artículos 5 a 20 del Convenio MEDICRIME.

70 Artículo 21 del Convenio MEDICRIME. Cooperación internacional en materia penal. 1. Las Partes cooperarán entre sí, en la medida más amplia posible, de conformidad con las disposiciones del presente Convenio y en aplicación de los instrumentos internacionales y regionales pertinentes aplicables, los acuerdos basados en legislaciones uniformes o recíprocas y su Derecho interno, en el marco de cualquier investigación o procedimiento relativo a los delitos tipificados con arreglo al presente Convenio, y en particular mediante la aplicación de medidas de embargo y decomiso. 2. Las Partes cooperarán entre sí, en la medida más amplia posible, de conformidad con los tratados internacionales, regionales y bilaterales pertinentes aplicables relativos a la extradición y a la asistencia judicial en materia penal en relación con los delitos tipificados con arreglo al presente Convenio. (La cursiva es añadida).

71 BOE núm. 142, de 13 de junio de 1980.

72 Capítulo VIII, artículos 23 a 25 del Convenio MEDICRIME. 
politizado que un órgano integrado de carácter judicial o cuasi judicial- es el encargado de velar por la correcta ejecución de los compromisos asumidos por los Estados parte en este Convenio, no concretándose cómo desarrollará esta función de control, por ejemplo, exigiendo memorias o informes anuales a los Estados parte en el mismo ${ }^{73}$. $\mathrm{Al}$ adoptar un mecanismo de supervisión blando, el Convenio MEDICRIME sigue la línea tradicional de los tratados multilaterales de carácter universal en los que la aspiración de vincular en los mismos al mayor número posible de países conlleva el precio de rebajar el contenido de los compromisos asumidos y el control de su cumplimiento ${ }^{74}$. El carácter blando se este mecanismo se reafirma en el artículo 31 que prevé un mecanismo no vinculante de solución de controversias entre los Estados parte en el Convenio MEDICRIME en relación con su aplicación ${ }^{75}$, por ejemplo, para el supuesto de que uno de los Estados pretenda su terminación o la suspensión de su aplicación como consecuencia del incumplimiento de las obligaciones asumidas por otro Estado parte ${ }^{76}$.

73 Artículo 25 del Convenio MEDICRIME. Funciones del Comité de las Partes. 1. El Comité de las Partes se encargará de supervisar la aplicación del presente Convenio. El reglamento del Comité de las Partes definirá el procedimiento de evaluación de la aplicación del Convenio adoptando un enfoque multisectorial y multidisciplinar. 2. El Comité de las Partes se encargará igualmente de facilitar la recogida, análisis e intercambio de información, experiencias y buenas prácticas entre los Estados, con vistas a mejorar su capacidad para prevenir y combatir la falsificación de productos médicos y delitos similares que supongan una amenaza para la salud pública. El Comité de las Partes podrá recibir la asistencia de otros comités u órganos pertinentes del Consejo de Europa. 3. El Comité de las Partes se encargará también, en su caso: a. de facilitar la utilización y aplicación efectivas del presente Convenio, en particular, identificando cualquier problema que pudiera surgir así como los efectos de cualquier declaración o reserva formulada con arreglo al presente Convenio; b. de emitir un dictamen sobre cualquier cuestión relativa a la aplicación del presente Convenio y facilitar el intercambio de información sobre los cambios jurídicos, políticos o técnicos importantes; c. de dirigir recomendaciones específicas a las Partes sobre la aplicación del presente Convenio. 4. El Comité Europeo para Problemas Penales (CEPC) recibirá información periódica sobre las actividades mencionadas en los apartados 1, 2 y 3 del presente artículo.

74 El Acuerdo de París de 12 de diciembre de 2015 sobre el Cambio climático es un ejemplo de esta práctica internacional. Vid. Instrumento de ratificación por el Reino de España de este instrumento publicado en BOE núm. 28 de 2 de febrero de 2017.

75 Artículo 31 del Convenio MEDICRIME. Solución amistosa. El Comité de las Partes, en estrecha colaboración con el Comité Europeo para Problemas Penales (CEPC) y los demás comités intergubernamentales o científicos competentes del Consejo de Europa, supervisará la aplicación del presente Convenio y facilitará en su caso la solución amistosa de toda dificultad que pudiera surgir en su aplicación.

76 De conformidad con el artículo 60 de la Convención de Viena de 23 de mayo 1969 sobre Derecho de Tratados. BOE núm. 142, de 13 de junio de 1980. 
Por su objeto y fin, es un tratado importante. El mercado mundial de medicamentos fraudulentos se estima que alcanza la cifra de 75.000 millones de dólares anualmente (un 10\% del comercio total de medicinas), explicable por el bajo riesgo que corren los criminales que participan en este negocio (con sus actos calificados normalmente como faltas y no como delitos), en comparación con otros actos al margen de la ley frente al posible beneficio, en gran medida a causa del elevado precio de los medicamentos originales frente al bajo coste de sus copias. Por categorías, a la cabeza de los productos falsificados están los productos para tratamiento de disfunción eréctil, las sustancias adelgazantes, psicoactivas y dopantes. Le siguen, las medicinas «esenciales» como analgésicos, antibióticos y retrovirales ${ }^{77}$.

Algunos autores han llegado a afirmar -en mi opinión de manera exagerada aunque explicable por el volumen mundial de este negocio ilícito y por el ritmo de crecimiento en los últimos años- que la falsificación de medicamentos es la nueva amenaza global de alcance mundial a la que se enfrenta en la actualidad la comunidad internacional ${ }^{78}$. Hay que matizar, sin embargo, que siendo una amenaza que concierne a todos los países del mundo, no sólo a los europeos, esa afección se realiza de desigual modo pues es en el caso de los países en desarrollo -con África a la cabeza- en los que más graves efectos se manifiestan $^{79}$. Además, aceptando que es una amenaza global habría que concluir desde el Derecho internacional que el Convenio MEDICRIME es un fracaso pues si problemas globales requieren soluciones globales ${ }^{80}$, un tratado

77 Venhuis, B. et al., «Operation resistance: A snapshot of falsified antibiotics and biopharmaceutical injectables in Europe», Drug Testing and Analysis, vol. 8, 2016, p. 398.

78 Romeo CaSABOna, C. M. et al., «International stretegies in fighting against medicaments fraud and other similar offences. The MEDICRIME Convention», Crime Law Soc. Change, Springer, 2016, p. 3.

79 La cifra de fallecimientos en África a causa de medicamentos falsos contra la malaria se estima en cien mil personas por año. Vid. ANDREU-MARCH, M. et al., «Turn back crime: medicamentos ilegales y papel del farmacéutico comunitario», Farmacéuticos comunitarios, vol. 8, n ${ }^{\circ}$, 2016, p. 26. Las causas de esta desigual incidencia entre países son evidentes: junto a las deficiencias de su marco jurídico y la falta de controles correspondientes, hay que sumar los limitados recursos que se puede destinar en ellos para la compra de medicamentos genuinos. Así, si el porcentaje de medicamentos falsificados equivale a un $10 \%$ del volumen global, discriminando por renta per cápita, ese porcentaje alcanza al 30\% tratándose de países menos avanzados de África, Asia y América. En antiguas Repúblicas de la Unión Soviética el porcentaje de productos médicos falsificados ronda el 20\%. TARDIF, E., «Medicamentos falsificados: una píldora difícil de tragar y un reto sanitario global», op. cit., p. 594.

80 Así se entiende desde el Derecho internacional público en relación con cuestiones biojurídicas: vid. GARCía SAN José, D., «Epigenética y gestación por sustitución: más razones a favor de una regulación internacional para un negocio global», Anuario Mexicano de Derecho Internacional, 
que a fecha de 16 de mayo de 2017 compromete sólo a nueve ${ }^{81}$ de los cerca de doscientos Estados que integran la comunidad internacional, no admite otro calificativo en mi opinión.

\section{Análisis crítico del Convenio MEDICRIME}

Hasta el Convenio MEDICRIME, la lucha de la comunidad internacional contra la falsificación de medicamentos se había realizado desde el plano de la protección de derechos de propiedad intelectual, dejando de lado la dimensión de la salud pública ${ }^{82}$. Ahora, la consideración novedosa de estas conductas como una amenaza grave para la salud pública y el diseño de la protección de las víctimas frente a estas prácticas delictivas como uno de sus ejes centrales (preámbulo y artículo 1), hacían en principio idóneo el Consejo de Europa para promover esta acción concertada de la comunidad internacional, a la luz de la tradición normativa de esta Organización desde la perspectiva del Estado de Derecho y la protección de los derechos humanos. Ahora bien, otras consideraciones deben ser tenidas en cuenta para valorar si la apuesta del Consejo de Europa ha sido o no un acierto. En concreto, su proceso de gestación y el carácter rígido de sus disposiciones no ayudan a su amplia aceptación por parte de los Estados que integran la comunidad internacional.

El Convenio MEDICRIME es un tratado internacional que ha tenido un proceso de elaboración relativamente corto: desde que la Asamblea Parlamentaria del Consejo de Europa presentara en 2007 un informe alertando sobre la necesidad de que esta Organización Internacional adoptara un tratado internacional en esta materia ${ }^{83}$, hasta su firma en Moscú el 28

vol. XVII, 2017, pp. 329-368; y, en el ámbito específico de la falsificación de medicamentos: vid. AlarCón-JimÉNEZ, Ó., «The MEDICRIME Convention. Fighting against counterfeit medicine», Eurobealth, vol. 21, nº 4, 2015, p. 26.

81 Esos Estados son: Albania, Armenia, Bélgica, Francia, Hungría, Moldavia, España, Ucrania y Guinea. Sólo nueve Estados que, además, no son los más relevantes desde el punto de vista del objeto y fin del Convenio MEDICRIME, como por ejemplo China, Rusia o India, en donde mayor número de falsificaciones de medicamentos se producen, o países de África o Asia donde mayor número de pacientes los consumen.

82 Romeo Casabona, C. M. et al., «International strategies in fighting against medicaments fraud and other similar offences. The MEDICRIME Convention», op. cit. p. 4.

83 «Need for a Council of Europe Convention on the Supression of Counterfeiting and Trafficking in counterfeit good», Doc. 11227 de la Asamblea Parlamentaria del Consejo de Europa, adoptado el 20 de abril de 2007. Disponible en internet en http://assembly.coe.int/nw/xml/ XRef/Xref-XML2HTML-en.asp?fileid=17538\&lang=en [visitado: 22 de mayo de 2017]. 
de noviembre de 2011, apenas pasaron cuatro años. Esta rapidez, pese a la magnitud del problema al que se refiere el tratado en cuestión, puede explicarse por varias razones: en primer lugar, porque como se ha destacado insistentemente, no es un instrumento legal relativo a la protección de los derechos de protección intelectual ${ }^{84}$. En segundo lugar, hay que considerar el contexto en el que se adopta: el marco europeo en sentido amplio, el Consejo Europeo: 48 Estados de Centro y Este de Europa, incluyendo a la Federación Rusia y a Turquía, con posibilidad de que sea además ratificado por otros Estados del resto del mundo. La dilatada experiencia del Consejo de Europa en la adopción de tratados internacionales era garantía de que la negociación y adopción del Convenio MEDICRIME sería fácil, como la realidad lo ha comprobado.

Ahora bien, precisamente lo que es fortaleza esconde la debilidad de este instrumento convencional. En efecto, la práctica internacional muestra que los tratados multilaterales generales, esto es, aquellos que más que proteger los derechos e intereses de los Estados en sus relaciones sinalagmáticas (do ut des) aspiran a regular y proteger un interés superior (estableciendo obligaciones erga omnes de cada Estado con respecto a la Comunidad internacional) se caracterizan por un proceso complejo de negociación -a menudo mediante la técnica del consenso respecto de acuerdos en bloque (package deal)- en el que participan países representantes de los distintos sistemas políticos y económicos del mundo, incluyendo a los países especialmente interesados. No se pone el acento en el número de Estados participantes en este proceso de codificación internacional sino en la calidad de los participantes. En otros términos, se trata de un concepto cualitativo más que cuantitativo de la comunidad internacional: la comunidad internacional en su conjunto y no el conjunto de Estados que integran la comunidad internacional. Esta idea ha sido expresada magistralmente por el profesor Dupuy al distinguir entre communauté des États dans leur ensemble (comunidad internacional en sentido cuantitativo) y la communauté des États dans son ensemble (comunidad internacional en sentido cualitativo $^{85}$. En un mundo donde la asunción de obligaciones internacionales por los Estados sigue regida en gran medida por el principio ex consensu

84 Con ello se descarta un ámbito en el que los intereses individuales de los Estados hace de freno para alcanzar compromisos internacionales en los que deban considerarse también los intereses de otros Estados o, incluso, el interés general de la propia comunidad internacional.

85 Según la expresión acuñada por el profesor P. M. DuPUY en su manual Droit International Public, $7^{\mathrm{a}}$ ed., Pedone Paris, 2004, pp. 752 a 754. 
advenit vinculum ${ }^{86}$, la estrategia que funciona es implicar al mayor número de Estados posibles en el proceso de gestación de un tratado y no sólo confiar en que la bondad del fin perseguido va a ser suficiente para vencer voluntades y hacer que desinteresadamente asuman obligaciones internacionales que supongan una limitación de su soberanía ${ }^{87}$.

En este sentido, la experiencia demuestra que los tratados internacionales adoptados en el seno del Consejo de Europa no tienen una masiva adhesión de Estados fuera del contexto de la propia organización regional. No alcanzan el grado de tratados multilaterales de alcance global, ni directa ni indirectamente; esto es, por el número de Estados que son parte en los mismos o en la medida en que sirven de inspiración para otros tratados de ámbito universal. Todavía se sigue viendo con recelo en diversas partes del mundo las propuestas normativas que llegan de Europa como reflejo de aspiraciones neocoloniales, irrespetuosas con la diversidad cultural de la sociedad mundial y en este sentido, otros ámbitos de cooperación política institucionalizada más representativos de dicha diversidad, como las Naciones Unidas ${ }^{88}$ o la Organización Mundial de la Salud ${ }^{89}$, parecerían escenarios más idóneos para

86 Recogido expresamente en el artículo 34 de la Convención de Viena de 23 de mayo de 1969 sobre Derecho de Tratados. BOE núm. 142, de 13 de junio de 1980.

87 Numerosos autores sostienen que siendo un problema a escala mundial la respuesta debe serlo igualmente proporcionada, esto es, global. Vid. FaYZRAKHMANOV, N. F., «Fighting trafficking of falsified and substandard medicinal products in Russia», International fournal of Risk \& Safety in Medicine, vol. 27, 2015, pp. 37-40.

88 La Oficina de Naciones Unidas contra la Droga y el Delito (https://wwwunodc.org/unode/ es/) (UNODC en sus siglas en ingles) y la Convención de las Naciones Unidas contra la Delincuencia Organizada Transnacional, hecha en Nueva York el 15 de noviembre de 2000, BOE núm. 233 de 29 de septiembre de 2003 (UNTOC en sus siglas en inglés), con un alcance universal al vincular a 174 Estados. Si bien, como reconoce Mackey, el punto débil de esta solución estriba de un lado, en el limitado objeto material de este Convenio, sólo las sustancias narcóticas y sicotrópicas no cubriendo la falsificación del resto de medicamentos; por otro lado, el UNTOC incluye algunas excepciones por motivos científicos y médicos -no previstas en el Convenio MEDICRIME- y que podrían ser aprovechados para falsificación de medicamentos legales. MACKEY, T. K., «Global Health Diplomacy and the Governance of Counterfeit Medicines: A Mapping Exercise of Institutional Approaches», Fournal of Health Diplomacy, 2013, pp. 10-11.

89 En particular, el Grupo Especial Internacional contra la Falsificación de Productos Médicos (IMPACT por sus siglas en inglés) establecido en 2006 por esta Organización. www.who.int/ impact/es Si bien hay autores que dudan de la pertinencia de este foro pues temen que termine beneficiando a los objetivos de los países desarrollados en materia de propiedad intelectual. DounIs, C., «Enforcing Intellectual Property Rights Via EU Border Regulations: Inhibiting Access to Medicine or Preventing Counterfeit Medicine?», Brooklyn Fournal of International Law, vol. 36, 2011, p. 734. 
la elaboración de un tratado que se aspira que sea universal o, al menos, ampliamente ratificado por el mayor número posible de Estados $^{90}$.

A mayor abundamiento, una de las críticas que los autores hacen al Convenio MEDICRIME es que su elaboración ha sido conducida no con toda la transparencia y publicidad que la ocasión requería ${ }^{11}$, con un marcado enfoque europeo y con exclusión de actores relevantes de ámbito europeo y extra euro$\mathrm{peo}^{92}$. En particular, algunos comentaristas señalan que la industria farmacéutica de productos genéricos, habiendo sido excluida de su gestación, mantiene una actitud reacia al Convenio MEDICRIME ${ }^{93}$.

Entre las consecuencias que se derivarían del modus operandi del Consejo de Europa y de sus Estados miembros adoptando el Convenio MEDICRIME figuran, entre otras, la utilización de términos propios a los efectos de la propia convención que, no habiendo sido consensuados con actores no participantes, hace difícil la adhesión de éstos a los mismos. El concepto de falsificación recogido en el Convenio MEDICRIME no coincide con el establecido por la Organización Mundial del Comercio ni por la Organización Mundial de la Salud ${ }^{94}$. De este modo, frente a otros instrumentos internacionales, bajo la rúbrica «medicamento falsificado», el Convenio MEDICRIME incluye un medicamento elaborado para fines de investigación (art. 4.b.iii) que contenga una presentación engañosa de la identidad o de la fuente (art. 4.j.) Siendo práctica habitual en los ensayos clínicos el no revelar o indicar con falsos datos las medicinas y placebos, o ambos, los investigadores se exponen a incurrir en

90 En este sentido discrepamos de los autores que piensan que el Consejo de Europa era el foro adecuado para la adopción de un tratado como MEDICRIME. Romeo CASABONA, C. M. et al., «International strategies in fighting against medicaments fraud and other similar offences. The MEDICRIME Convention», op. cit., p. 7.

91 Attaran, A., «Europe and the United Nations: Clinical Trials, Not Criminal Trials», Harvard Public Health Review, Special Commentary (February 2015). Disponible en: (Delivery.cfm/ SSRN_ID2748247_code333294.pdf?abstracid=2748247\&mirid=1\&type=2) [visitado: 24 de febrero de 2017].

92 MACKeY, T. K., «Global Health Diplomacy and the Governance of Counterfeit Medicines: A Mapping Exercise of Institutional Approaches», op. cit., p. 10. ATTARAn, A. y BATE, R., «A Counterfeit Drug Treaty: Great Idea, Wrong Implementation», The Lancet, vol. 376, 2010, p. 1447. Estos autores destacan, por ejemplo, la presencia de representantes líderes de la industria farmacéutica (Sanofi-Aventis) pero la ausencia de representantes de los fabricantes de genéricos farmacéuticos.

93 Buckley, G. y Gostin, L. (eds.), Countering the Problem of Falsified and Substandard Drugs, Washington, D. C., The National Academies Press, 2013, p. 297. AtTaran, A. y Bate, R., «A Counterfeit Drug Treaty: Great Idea, Wrong Implementation», op. cit., pp. 1446-1448.

94 Cvetanovski, F. et al., «Counterfeiting of medicines as an infringement of the intelectual property rights», Macedonian pharmaceutical bulletin, vol. 62, n 1, 2016, p. 85. 
una conducta tipificada por esta disposición que no distingue entre falsificación benevolente de otra malevolente ${ }^{95}$.

El concepto de «producto médico», esto es, los medicamentos y los dispositivos médicos (art. 4) no es susceptible de reserva por los Estados que se adhieran al Convenio MEDICRIME. Así, por ejemplo, se considera en esa misma disposición que medicamento de uso humano y veterinario incluye, entre otros, el medicamento elaborado para fines de investigación» [art. 4.b) iii.]. El problema de esta rígida definición que no admite matización estriba, como ya se ha señalado, en que se utiliza una definición no consensuada entre los Estados, con otras Organizaciones Internacionales como la Organización Mundial del Comercio o la Organización Mundial de la Salud ni compartida por la comunidad científica implicada en ensayos clínicos ${ }^{96}$.

La Convención de Viena de 23 de mayo de 1969 sobre Derecho de Tratados expresamente permite que al firmar un tratado se introduzcan reservas o declaraciones interpretativas que sirven a que determinados tratados alcancen un elevado número de ratificaciones. Es el precio a pagar por la multilateralidad, siempre que no vayan contra el objeto y fin del tratado. ¿Es la definición de medicamento un elemento esencial y necesario para salvaguardar el objeto y fin del Convenio MEDICRIME previsto en su artículo $1 ?^{97}$ Entiendo que la respuesta es negativa, a la luz del informe explicativo ${ }^{98}$. En efecto, en el apartado 33 (en la página 5 del mismo) se afirma que la definición de producto médico a los efectos del Convenio está inspirado en el Derecho de la Unión Europea, en esencia, la Directiva 2011/62/EU de 8 de junio de 2011, que modifica la Directiva 2001/83/EC por la que se establece un código comunitario sobre medicamentos de uso humano, en lo relativo a la prevención de la entrada de medicamentos falsificados en la cadena de suministro legal ${ }^{99}$, y el Reglamento (UE) n ${ }^{\circ} 536 / 2014$

95 Attaran, A. et al., «Why and How to Make an International Crime of Medicine Counterfeiting», Fournal of International Criminal fustice, vol. 9, nº 2, 2011, p. 337.

96 ID., «Stopping murder by medicine: introducing the model law on medicine crime. American Journal of Tropical Medicine and Hygiene, vol. 92, suppl. 6, 2015, pp. 127-132.

97 Artículo 1 del Convenio MEDICRIME. Objeto y finalidad: «1. El presente Convenio tiene por objeto prevenir y combatir las amenazas que gravitan sobre la salud pública: a. penalizando determinados actos; protegiendo los derechos de las víctimas de los delitos establecidos en virtud del presente Convenio; c. promoviendo la cooperación nacional e internacional. 2. Con el fin de asegurar la aplicación efectiva de sus disposiciones por las Partes, el presente Convenio establece un mecanismo específico de seguimiento».

98 https://www.coe.int/t/dghl/standardsetting/cdpc/CDPC\%20documents/Medicrime\%20Convention_rapport\%20explicatif_F.pdf [visitado: 23 de mayo de 2017].

99 DOUE L 174, de 1 de julio de 2011, pp. 74-87. 
del Parlamento Europeo y del Consejo, de 16 de abril de 2014, sobre los ensayos clínicos de medicamentos de uso humano, y por el que se deroga la Directiva 2001/20/CE ${ }^{100}$. Es decir, una normativa específica de una Organización Internacional de integración como es la Unión Europea se pretende extenderla primero a otros Estados europeos, los del Consejo de Europa, algunos de los cuales están muy distantes en cuanto a la regulación en este ámbito, y más tarde, a cualquier Estado del mundo que desee adherirse al Convenio MEDICRIME. Resulta difícil pensar, llegados a este punto, que los redactores de este Convenio hayan sido tan soberbios o tan ignorantes como para caer en el error de vincular el artículo 4 (definiciones) al objeto y fin del Convenio MEDICRIME, excluyendo por ello, cualquier reserva a su contenido ${ }^{101}$. Y sin embargo, a la luz del enunciado del artículo 30 del propio Convenio ${ }^{102}$, la realidad parece ser esta, dando un argumento más a aquellos que dudan de que el número de ratificaciones del Convenio MEDICRIME llegue a ser lo suficientemente significativo.

\section{Claves de Una ACCión InStitucionalizada DE La COMUNidAD INTERNACIONAL PARA EL ACCESO A MEDICAMENTOS SEGUROS COMO UN GLOBAL COMMON DE CARÁCTER INTANGIBLE A PARTIR DEL GLOBAL HEALTH LAW}

De entrada, debe aclararse que el concepto de Global Law que se asume en este trabajo coincide con el defendido por la profesora Iglesias Vázquez -desde el sentido común- cuando concluye que:

«es, en definitiva, el Derecho internacional -público- lo que está detrás de aquello que algunos llaman Global Law. El éxito de los diferentes acuerdos

100 DOUE L 158, de 27 de mayo de 2014, pp. 1-76.

101 Adviértase, en este sentido, que la referencia al Derecho de la Unión Europea es muy genérica en el preámbulo: «Teniendo debidamente en cuenta otros instrumentos jurídicos y programas internacionales pertinentes, desarrollados especialmente por la Organización Mundial de la Salud, en particular los trabajos del grupo IMPACT, y por la Unión Europea, así como los desarrollados en el marco del G-8» (La cursiva es añadida). De ahí la sorpresa en hacer depender un concepto tan importante como el del «medicamento falsificado» exclusivamente de disposiciones de Derecho derivado de la Unión Europea que sólo vinculan a 28 de los 48 Estados miembros del Consejo de Europa.

102 Artículo 30 del Convenio MEDICRIME. Reservas. «1. No se admitirá ninguna reserva a las disposiciones del presente Convenio, con excepción de las expresamente establecidas». El artículo 4 no prevé reservas por lo que de conformidad con el artículo 19 de la Convención de Viena sobre Derecho de los Tratados de 1969, a efectos prácticos, es igual a una prohibición a su formulación. 
internacionales es lo que hace emerger la unificación y armonización de normas en la sociedad internacional» ${ }^{103}$.

En este sentido, la interpretación que seguimos del Global Health Law ${ }^{104}$ no comparte las críticas que se hacen de la estatalidad de la regulación internacional de estas cuestiones desde el paradigma de la soberanía estatal ${ }^{105}$. Antes al contrario, nos parece esencial mantenerla siempre que se complemente, como venimos defendiendo en este estudio, con la rendición de cuentas de entidades no estatales que tienen una responsabilidad en el derecho a la salud a escala global, como es el caso, en particular, de las empresas farmacéuticas.

Uno de los principales obstáculos para la aproximación multidisciplinar, integradora y transversal al problema global del acceso seguro a medicamentos esenciales en todo el mundo sigue siendo la falta de consenso respecto de una terminología a escala mundial respecto de cuestiones tales como medicamentos esenciales, de mala o baja calidad, espurios, con rotulación falsa, falsificados o fraudulentos. Según la Organización Mundial de la Salud, los medicamentos esenciales son «los que satisfacen las necesidades prioritarias de salud de la población. Se seleccionan teniendo debidamente en cuenta su pertinencia para la salud pública, pruebas de su eficacia y seguridad y su eficacia comparativa en relación con el costo ${ }^{106}$. No parece una definición pro-

103 IgLESIAS VÁZquez, M., «Globalización, Globalización Jurídica, Global Law y Derecho Internacional Privado», Cuadernos de Derecho Transnacional, vol. 9, nº 1, 2017, p. 234.

${ }^{104}$ En la doctrina es posible encontrar tantas definiciones de Global Health Law como autores. A los efectos de este estudio seguiré la definición de Lawrence Gostin: «El Derecho de Salud Global es un sector del Ordenamiento Jurídico Internacional que abarca las normas legales, procesos e instituciones necesarias para crear las condiciones necesarias para que las personas en todo el mundo alcancen el nivel más alto posible de salud física y mental. Este sector normativo busca facilitar el comportamiento promotor de la salud entre los actores clave que influyen significativamente en la salud pública, incluyendo Organizaciones Internacionales, Gobiernos, empresas, fundaciones, los medios de comunicación y la sociedad civil. Los mecanismos de la legislación sanitaria mundial deberían estimular la inversión en investigación y desarrollo, movilizar recursos, establecer prioridades, coordinar actividades, supervisar el progreso, crear incentivos y hacer cumplir las normas. El estudio y la práctica del Derecho de Salud Global deben guiarse por el valor general de la justicia social, que requiere una distribución equitativa de los servicios de salud, en particular para beneficiar a las poblaciones más pobres del mundo». (La traducción es nuestra del original en inglés). Gostin, L. y TAYLOR, A. L., «Global Health Law: A Definition and Grand Challenges», Public Health Ethics, vol. 1, n 1, 2008, p. 55.

105 Gostin, L. O. y TaYlor, A. L., «Global Health Law: A Definition and Grand Challenges», op. cit., p. 57.

106 World Health Organization: The selection and use of essential medicines. Report of the WHO Expert Committee, 2002, including the $12^{\text {th }}$ Model List of Essential Medicines. Technical Report Series 
blemática. Sin embargo, en 2002 la Organización Mundial de la Salud cambió su «Model List» de medicamentos esenciales -establecida por primera vez en 1977 y actualizada desde entonces cada dos años- incluyendo nuevas medicinas con independencia de su costo si se probaban ser más eficaces con respecto a las existentes. Hasta entonces se habían incluido sólo las más baratas -genéricas o con precio bajo por no tener derechos de propiedad intelectual respaldándolas- con el fin de que fueran asequibles a todos los pacientes que las necesitaran con independencia del país donde residieran. Las listas de medicamentos esenciales siguiendo el modelo de la Organización Mundial de la Salud, fueron asumidas por Organismos internacionales como UNICEF, el ACNUR, así como por la mayoría de ONGs que desarrollan labores humanitarias como un poderoso medio de promoción del acceso equitativo a la salud (bealth equity) $)^{107}$.

La nueva situación asumida por la Organización Mundial de la Salud desde 2002 recibió críticas porque en los países en desarrollo los gastos farmacéuticos suponen la segunda mayor partida dentro del gasto en sanidad, sólo detrás de los salarios del personal sanitario, en la medida en que las medicinas esenciales son ahora muy caras. La mayor parte de los presupuestos de medicamentos de los países en desarrollo están por debajo de 30 dólares por persona y año; en treinta y ocho países, son inferiores a 2 dólares por persona y año. Por ello se ha defendido que sólo se incluyan en las listas de medicamentos esenciales nuevos medicamentos que verdaderamente respetan el principio de la mejor relación calidad-precio, descartando la introducción de aquellos nuevos medicamentos que, siendo mucho más caros, sólo aportan una ligera mejora desde el punto de vista del tratamiento médico ${ }^{108}$.

Junto a la conceptualización de los medicamentos esenciales, en el seno de la Organización Mundial de la Salud se trabaja por alcanzar un significado común y global que clarifique lo que los Estados entienden que son medica-

No. 914, Geneva, 2003, p. 15. Como se indica en este documento, los medicamentos esenciales deben estar disponibles en los sistemas de salud en todo momento, en cantidades suficientes, en las formas farmacéuticas apropiadas, con garantía de la calidad e información adecuada, a un precio que los pacientes y la comunidad puedan pagar. Http://apps.who.int/medicinedocs/pdf/ h3006s/h3006.pdf [visitado: 8 de mayo de 2017].

107 Barbui, C. y Purgato, M., «Decisions on WHO's essential medicines need more scrutiny», op. cit., p. 1.

${ }^{108}$ HogerzeIL, H. V., «The concept of essential medicines: lessons for rich countries», British Medical fournal, vol. 329, 2004, p. 1170. 
mentos ilegales ${ }^{109}$ a través del Mecanismo de Estados Miembros ${ }^{110}$. Este órgano de la Organización Mundial de la Salud introdujo en su plan de trabajo un parágrafo 8 cuyo apartado «c» se refería a la creciente relación entre la falta de acceso a medicamentos y la aparición de productos médicos de mala calidad, espurios, con rotulación falsa, falsificados o fraudulentos (productos médicos $S S F F C$ por sus siglas en inglés: substandard/ spurious/ falselylabeled/ falsified/ counterfait medical products) ${ }^{111}$ al tiempo que se proponía una clasificación, a la espera de que sea aceptada o rechazada por los Estados miembros de la Organización, que pretende ser inclusiva de todos los supuestos posible:

- Authorized medical products: productos médicos que cumplen la normativa nacional y regional.

- Substandard medical products: son productos médicos autorizados que no cumplen los estándares de calidad o sus especificaciones, o ambos.

- Unregistered/unlicensed medical products: productos médicos que no han sido sometidos a evaluación y/o aprobación por parte de las autoridades reguladoras a nivel nacional o regional, para el mercado en el que son comercializados y distribuidos.

- Falsified medical products: productos médicos que deliberadamente o de forma fraudulenta representan mal su identidad, composición u ori$\operatorname{gen}^{112}$.

De esta clasificación se deduce que los productos médicos que no hayan sido autorizados para ser comercializados en un país, sólo por ese hecho no deberían ser considerados como falsificados. Así, frente al término «counterfait»,

109 A través de un órgano ad hoc denominado Mecanismo de los Estados Miembros (MSM en sus siglas en inglés), creado en el punto 4 de la Resolución WHA 65.19, de 26 de Mayo de 2012 sobre Substandard/Spurious/Falsely-labelled/Falsified/Counterfeit Medical products (SSFFC Medical Products).

110 Creado en el punto 4 de la Resolución WHA 65.19 de 26 de mayo de 2012 relativa a productos médicos de mala calidad, espurios, con rotulación falsa, falsificados o fraudulentos.

111 Documento A/MSM/2/6, Annex 2, paras. 9 y ss., de 4 de noviembre de 2016 «Understanding the links between Access to quality, safe, efficacious and affordable medical products and the emergence of substandard, sporious, flasely-labelled, flasified, counterfeit (SSFFC) medical products», disponible en http://apps.who.int/gb/ssffc/pdf_files/MSM5/A_MSM5_2-en.pdf [visitado: 22 de mayo de 2017].

112 Documento $\mathrm{A} / \mathrm{MSM} / 5 / 7$, de 23 de noviembre de 2017, en el que relata el quinto encuentro del grupo de trabajo informal creado en 2015 dentro del Mecanismo de Estados Miembros, encargado de alcanzar un significado común y global que clarifique lo que los Estados consideran que son productos médicos SSFFC. Disponible en http://apps.who.int/gb/ssffc/pdf_files/ MSM5/A_MSM5_7-en.pdf [visitado: 22 de mayo de 2017]. 
propio del ámbito de protección de los derechos de propiedad intelectual, se prefiere el término «falsified» en el ámbito de la Organización Mundial de la Salud, sin que a día de hoy se haya alcanzado un consenso terminológico al respecto. De ahí el término SSFFC (substandard/ spurious/ falsely-labelled/ falsified/ counterfait medical products) con el que trabaja el Mecanismo de Estados Miembros desde 2012, incluyendo todas las acepciones posibles de los medicamentos ilegales.

Algunos autores, abogan por una mayor cooperación entre las distintas Organizaciones Internacionales, estableciendo una sinergia de actuación desde el respectivo ámbito competencial de cada una de ellas. Esta posible solución, siguiendo a Mackey ${ }^{113}$, que consiste en una acción concertada de varias Organizaciones Internacionales, es algo frecuente en la órbita de Naciones Unidas, cooperando con la Organización Mundial de la Salud para la erradicación de la malaria, o con la FAO, para el Programa Mundial de Alimentos, junto a actores no gubernamentales como médicos sin fronteras y otras ONGs. Así, la OMS podría centrarse en aspectos de salud pública y en potenciar el acceso a medicamentos seguros, fortaleciendo los sistemas nacionales de salud y los sistemas de vigilancia, conduciendo los estudios epidemiológicos sobre medicinas falsas ${ }^{114}$; la Oficina de Naciones Unidas contra la Droga y el Delito (UNDOC) ${ }^{115}$, en cooperación con el Consejo de Europa, se ocuparían de la planificación y ejecución de medidas contra el comercio fraudulento de medicinas por parte del crimen organizado y agencias como interpol serían responsables de acciones represivas sobre el terreno, como la acción denominada PANGEA, que en su octava edición en 2015 supuso una operación conjunta en 115 países con notables resultados ${ }^{116}$.

En este escenario de acción concertada, los actores no gubernamentales ocuparían un relevante papel: las asociaciones de consumidores y de defensa de

\footnotetext{
113 Mackey, T., «Global Health Diplomacy and the Governance of Counterfeit Medicines: A Mapping Exercise of Institutional Approaches», op. cit., p. 12.

114 Buckley, G. y Gostin, L. (eds.), Countering the Problem of Falsified and Substandard Drugs, op. cit., pp. 297 y ss.

115 Vid. nota a pie $\mathrm{n}^{\circ} 88$.

116 MackeY, T. K., «Global Health Diplomacy and the Governance of Counterfeit Medicines: A Mapping Exercise of Institutional Approaches», op. cit., p. 12. A raíz de la operación PANGEA VIII se cerraron 2.414 sitios web, de detuvieron 156 personas y la incautación de 20,7 millones de productos falsificados. Frente a estos datos globales, en España la operación se saldó sólo con 19 personas detenidas, acusadas de cuatro delitos y el registro de ciento noventa y seis infracciones administrativas. ANDREU-MARCH, M. et al., «Turn back crime: medicamentos ilegales y papel del farmacéutico comunitario», op. cit., p. 29.
} 
los derechos de los pacientes, gracias a iniciativa europeas como la web Fakesbare $^{117}$, pero sobre todo las empresas farmacéuticas tendrían un importante papel a cumplir aportando relevante información que sirva para la concienciación de los riesgos que conlleva el consumo de medicamentos falsificados. De todo el comercio de medicinas por internet, la Organización Mundial de la Salud estima que alrededor del $50 \%$ de las medicinas vendidas por internet son falsas y el problema se agrava con las redes sociales en las que particulares interactúan con otros particulares comprando y vendiendo medicamentos in ningún control ${ }^{118}$. Esto supone un importante volumen de pérdidas para la industria farmacéutica. En consecuencia, cabría esperar su motivación por implicarse en la prevención de estas conductas criminales, concienciando a la población sobre los riesgos para su salud y vida derivados del consumo de productos médicos sin ninguna garantía ${ }^{119}$. En este sentido, se ha defendido líneas de actuación de la industria farmacéutica estableciendo laboratorios de prueba en diversos países para examen de muestras de medicinas de las que se sospeche su autenticidad -por ejemplo, en estrecha colaboración con el International Institute of Research Against Counterfeit Medicines (IRACM)- ${ }^{120}$, organizando cursos de formación dirigidos a fuerzas del orden y agentes gubernamentales encargados de valorar la autenticidad de medicamentos en circulación en sus respectivos países y de detectar sus falsificaciones, pero sobre todo, desarrollando actividades de comunicación, información, educación y creciente concienciación del público en general ${ }^{121}$.

La Humanidad se institucionaliza a través de las Naciones Unidas ${ }^{122}$ y la salud global como global common intangible de la especie humana debe ser objeto de una respuesta global liderada por esta Organización Internacional en estrecha coordinación con la Organización Mundial de la Salud, en tanto que

117 http://www.fakeshare.eu/es En esta web de la Unión Europea, de manera fácil y sencilla es posible verificar sitios web de venta de medicamentos y detectar si un medicamento o producto que se ofrece es legal o falsificado.

118 Incluso respecto de medicamentos que requieren prescripción médica como la vacuna contra la meningitis $\mathrm{B}$, que difícilmente asequible en las farmacias ante su escasez de suministros se presta fácilmente a su falsificación y comercio fraudulento. ANDREU-MARCH, M. et al., «Turn back crime: medicamentos ilegales y papel del farmacéutico comunitario», op. cit., p. 29.

119 CVETANOvSKi, F. et al., «Counterfeiting of medicines as an infringement of the intelectual property rights», op. cit., p. 86.

$120 \mathrm{http}: / /$ www.iracm.com/en/ [visitado: 22 de mayo de 2017].

121 Cvetanovski, F. et al., «Counterfeiting of medicines...», op. cit., p. 87.

122 FARAmiñán Gilbert, J. M., «De los espacios de interés internacional a los global commons», op. cit., p. 835 . 
autoridad internacional referente en temas de salud ${ }^{123}$. Ya hemos señalado que es perentorio una conceptualización integradora de los medicamentos ilegales para lograr una efectiva acción internacional que haga converger la garantía del derecho a la salud en su dimensión de acceso a medicamentos seguros, junto a una necesaria protección de los derechos de propiedad intelectual de las empresas farmacéuticas como contraprestación a sus inversiones en I+D en medicamentos. Como dice un viejo dicho: «una cosa es conocer el camino y otra hacerlo». Los progresos en el seno de la Organización Mundial de la Salud van muy lentos en parte debido, como ha sido señalado por el profesor Amir Attaran, porque aún no se ha logrado identificar objetivos compartidos por los actores concernidos: empresas farmacéuticas, ONGs y Gobiernos. Si bien todos quieren un acceso fiable a medicinas seguras y efectivas -por ello estando en contra de medicinas falsas que ponen en riesgo la salud- difieren, sin embargo, en qué peso dar a la protección de los intereses comerciales y a los intereses de salud pública en las medidas que deban adoptarse frente a la falsificación de medicamentos (anti counterfeiting) ${ }^{124}$.

En mi opinión, la Agenda 2030 es reflejo de un proceso iniciado hace años, en el que se evidencia un modelo de comunidad mundial que reivindica un paradigma de Derecho internacional integrado por el conjunto de obligaciones asumidas por los sujetos y actores internacionales en virtud de su consentimiento o al margen del mismo. Se trata, en efecto, de un paradigma de Global Law que, conforme a los valores universales expresados en la Carta de las Naciones Unidas, aspira a regular las relaciones de cooperación e interdependencia de los actores internacionales (no sólo Estados aunque respetando su papel principal) que integran la comunidad internacional, para preservar el bien común de la propia comunidad en su conjunto, a través de una gestión responsable, y por ello solidaria, de las competencias reconocidas a cada integrante de la misma.

La base consensual estatal como fuente de obligaciones internacionales cada vez más parece ser considerada no sólo desde una perspectiva individual -como lo ha sido tradicionalmente- sino también sobre una base colectiva consensual, frente a amenazas globales que son de interés general más que de interés común. Esto es, frente a cuestiones que tienen mayor relevancia para la Comunidad internacional de Estados en su conjunto que para los Estados que

\footnotetext{
123 Pons Rafols, X., «International Law and Global Health: an Overview», op. cit., p. 39.

124 ATtARAN, A. et al., «How to achieve international action on falsified and substandard medicines», op. cit., p. 1.
} 
integran tal Comunidad internacional ${ }^{125}$. La legitimidad de este nuevo orden normativo global, aún en formación se basa en la percepción de nuevas amenazas como cuestiones de interés general de la Comunidad internacional de Estados en su Conjunto y sobre una base consensual colectiva que prevalecería sobre la base consensual individual. Esto sería posible en el ámbito de la salud global, considerando los principios inferidos del Derecho Internacional tales como el principio de la dignidad intrínseca del ser humano del que se derivan obligaciones en orden a la protección de derechos humanos fundamentales como el derecho a la vida o el derecho a la salud ${ }^{126}$.

Desde hace años defiendo la tesis de que cuando frente a amenazas globales como es el caso de los graves riesgos para la salud pública en relación con el acceso a medicamentos, sólo puedan adoptarse aproximaciones multilaterales, entonces, la posición unilateral de uno o varios sujetos o actores internacionales no puede ser un obstáculo para la solución ${ }^{127}$. El punto débil de este argumento sigue siendo que, con carácter previo, debe resolverse la cuestión relativa a cómo distinguir una situación real que requiere una aproximación multilateral de una situación que algunos pretenden considerar como tal $^{128}$. En otros términos, debe aceptarse que la salud pública global es una de esas cuestiones que reclaman la aplicación de principios inferidos del Derecho Internacional que por ser aceptados universalmente serían principios del

125 Vid. GaRCía SAN JosÉ, D., «La elaboración del Derecho internacional más allá del consentimiento estatal: la emergente legalidad internacional de base consensual», Anuario Español de Derecho Internacional, vol. XXIV, 2008, pp. 107-139.

${ }^{126}$ Véanse al respecto las consideraciones que sobre este principio realizó la Corte Internacional de Justicia en su sentencia de 25 de Septiembre de 1997, ICf Reports 1997, parágrafos 49 a 59, en el case concerning the Gabčikovo-Nagymaros Project (Hungary/Slovakia). Aunque en su reciente fallo de 31 de marzo de 2014 en el caso Whaling in the Antarctic (Australia v. Japan: New Zealand intervening), no aparece ninguna mención expresa a dicho principio, el modo en que la Corte entra a valorar la controversia entre las partes aplicando el significado y alcance de la frase «for purposes of scientific research» como estándar de revisión de las obligaciones en el artículo VIII, parágrafo 1 de la ICRW, el objeto y fin de dicho Tratado -una cuestión de interés general para las generaciones presentes y futuras-, en mi opinión supone más una confirmación que una discrepancia con este principio. Vid. parágrafos 44-47, 56-58 y 67-69 de la sentencia.

127 Afirmación realizada respecto de un Estado o de un reducido grupo de Estados que es extensible a actores internacionales como las empresas farmacéuticas. GARCÍA SAN José, D., «El principio de necesidad ligado a la seguridad medioambiental como instrumento idóneo para reforzar la acción internacional, normativa e institucional, en materia de cambio climático», en R. Giles Carnero (coord.), Cambio Climático, Energía y Derecho Internacional: Perspectivas de Futuro, Thomson Reuter Aranzadi, Cizur Menor, 2012, p. 81.

128 GARCía SAN José, D., «Seguridad medioambiental y principio de necesidad en Bioderecho internacional», op. cit., p. 146. 
Global Law. Entiendo que la práctica internacional ofrece ejemplos suficientes para constatar que del principio de la dignidad intrínseca del ser humano se derivan obligaciones en relación con el derecho a la salud para Estados, Organizaciones Internacionales y para actores no estatales como las empresas farmacéuticas.

\section{Conclusión}

Frente al interés general relativo al acceso a medicamentos seguros, en sus dos principales dimensiones: impedir riesgos graves para la salud derivados del uso de medicamentos ilegales, de una parte, y asegurar el carácter accesible y asequible de medicamentos esenciales en todo el mundo, se debe considerar el derecho a la salud a escala mundial como un global common de carácter intangible frente al cual, desde el Derecho Internacional, debe asumirse una aproximación integral y global desde una perspectiva multidisciplinar; esto es, con aportaciones del Derecho Económico Internacional, el Derecho Internacional de los Derechos Humanos, las normas internacionales relativas a los estándares mundiales de salud establecidos por la Organización Mundial de la Salud y las disposiciones convencionales adoptadas por los Estados en el seno de la Oficina de Naciones Unidas contra la Droga y el Delito (UNDOC) y en la Interpol para la lucha contra el crimen organizado y contra falsificación de medicamentos, que está caracterizada doblemente. Es una perspectiva multidisciplinar, integradora y transversal, respectivamente, en el sentido de que junto a normas y obligaciones de carácter duro (hard law) entran en consideración otras que lo son de normatividad relativa (soft law) o sin carácter jurídico vinculante, en especial, teniendo por destinatario a entidades no estatales como son las empresas farmacéuticas, como las Human Rights Guidelines for Pharmaceutical Companies in Relation to Access to Medicines. Además, y en lo que hace a la transversalidad, se trata de normas, estándares de conducta y principios de comportamiento que no se detienen en las fronteras de un Estado, por afectar a intereses generales de la comunidad internacional en su conjunto y en la medida en que sus destinatarios ya no son sólo sujetos internacionales (Estados y Organizaciones Intergubernamentales), sino también actores (en particular las empresas farmacéuticas).

Uno de los principales obstáculos para la aproximación multidisciplinar, integradora y transversal al problema global del acceso seguro a medicamentos esenciales en todo el mundo sigue siendo la ausencia de una terminología 
consensuada a escala mundial respecto de cuestiones tales como medicamentos esenciales, de mala o baja calidad, espurios, con rotulación falsa, falsificados o fraudulentos. Esta situación es debida en gran medida a dos factores: de una parte, a la multipolarización de los foros de discusión sobre esta cuestión, contextualizados según los fines y objetivos de la Organización Internacional en cuestión: la OMC, la OMS, la UNDOC, la Interpol y recientemente el Consejo de Europa con el Convenio MEDICRIME. De otra parte, ha de considerarse la presencia distorsionadora de actores no estatales, como las empresas farmacéuticas que, con carácter general, no participan en estos foros institucionalizados sino de manera bilateral con los Estados. Por ello, parece necesario establecer cauces de cooperación institucionalizada entre Estados, Organizaciones Internacionales y actores no estatales utilizando fórmulas imaginativas a partir de la experiencia existente.

Así, por ejemplo, podría pensarse en conferencias periódicas, bianuales por ejemplo, a semejanza de la Conferencia sobre la Seguridad y Cooperación en Europa (que luego dio origen a la Organización para la Seguridad y Cooperación en Europa), con una representación tripartita de los Estados miembros siguiendo el modelo de la Organización Internacional del Trabajo: un agente gubernamental, un representante de la industria farmacéutica y un tercero en representación de las asociaciones médicas u ONGs comprometidas en la salud pública. Los representantes de los Estados se verían apoyados por una secretaría técnica que por el momento podría ser asumida por el Secretario General de Naciones Unidas quien contaría con el apoyo de cuatro subsecretarías temáticas: la de salud global, coordinada por el representante de la Organización Mundial de la Salud, e integrada por un grupo de Estados geográficamente representativos de la comunidad internacional (al igual que se sigue en la composición de los órganos de Naciones Unidas); la de asuntos económicos relacionados como los derechos de propiedad intelectual, que sería coordinada por el representante de la Organización Mundial del Comercio, y cuya composición sería conforme al mismo criterio seguido en la subsecretaría anterior; en tercer lugar, estaría la subsecretaría de asuntos humanitarios, coordinada por el Alto Comisionado de Naciones Unidas para los Refugiados y por la Oficina del Alto Comisionado de Naciones Unidas para los Derechos Humanos, que velaría por asegurar el acceso a medicamentos como un derecho humano, en especial, en situaciones de emergencia humanitaria; finalmente, en cuarto lugar, estaría la subsecretaría de asuntos policiales, coordinada por la Oficina de Naciones Unidas contra la Droga y el Delito (UNDOC) en colaboración con la Interpol, centrada en la lucha contra la criminalidad organizada en el 
ámbito de la falsificación de productos médicos y en su comercialización ilegal, y que al igual que las demás subsecretarías seguiría en su composición un criterio geográficamente representativo de los distintos sistemas políticos, económicos y culturales existentes. Cada una de estas subsecretarías tendría la tarea de elaborar documentos en su área respectiva de interés y de proponer medidas de actuación a corto y medio plazo para su debate y posterior asunción por los participantes en las respectivas Conferencias.

A fin de facilitar un rápida generalizada aceptación por parte los Estados participantes -en su triple composición antes defendida- las propuestas emanadas de estas Conferencias habrían de ser de carácter escalonado -siguiendo el modelo de los acuerdos marco en el ámbito de la protección del medio ambiente- en la medida en que siguiendo una estructura nomogenética compleja, en un primer momento, se trataría de adoptar sólo un acuerdo marco de carácter multilateral que contuviera sólo principios básicos consensuados respecto de objetivos generales futuros a alcanzar, dejando para un momento posterior la concreción de los mismos en futuros protocolos adicionales. Dichos protocolos prevén la constitución de órganos de carácter técnico integrados por representantes de aquellos Estados que ratifiquen los protocolos en cuestión, y cuentan con el poder de adoptar decisiones necesarias, tanto a nivel interno como externo, adoptando los anexos y apéndices que, a su vez, complementan los protocolos adicionales a los acuerdos marco. Se trata de un entramado legal complejo y dinámico que combina métodos tradicionales (treaty making) con otros más novedosos (technical law-making) especialmente idóneos para cuestiones complejas -como es el caso del acceso a medicamentos seguros en su doble dimensión- y en los que aspectos de tipo científico y técnico primarían sobre las consideraciones meramente políticas. 

NOTAS 
